\title{
How do Switching Costs Affect Market Concentration and Prices in Network Industries?
}

\author{
Jiawei Chen*
}

February 2014

\begin{abstract}
I investigate the effects of switching costs on the market outcome in network industries using a dynamic duopoly model of price competition in the presence of an outside option. I find that the role of switching costs depends on network effects and the outside option. Without a viable outside option, high switching costs can neutralize the tendency towards high market concentration associated with network effects, but with a viable outside option, switching costs increase market concentration. Furthermore, switching costs lower prices if network effects are modest and there exists a viable outside option, but generally raise prices otherwise.
\end{abstract}

\section{Introduction}

In this paper I investigate the effects of switching costs on industry dynamics and the market outcome in network industries. A product exhibits network effect if its value increases in the number of consumers who use it. A common feature of industries with network effects is the existence of finite switching costs: consumers can switch between networks but it is costly for them to do so, in terms of money and/or effort. For example, switching from one PC operating system to another requires substantial learning. Switching from one mobile phone network to another is also costly, as the consumer needs to inform her contacts of her new phone number (unless she

* Department of Economics, 3151 Social Science Plaza, University of California, Irvine, CA 92697-5100. E-mail: jiaweic@uci.edu. An earlier version of this paper was circulated under the title "Switching Costs and Dynamic Price Competition in Network Industries". I thank Dan Ackerberg, Volodymyr Bilotkach, Jan Brueckner, Daniel Cerquera, Matthew Chesnes, Linda Cohen, Ulrich Doraszelski, Amihai Glazer, Hugo Hopenhayn, Marc Rysman, Yossi Spiegel, and seminar participants at CSU Long Beach, Santa Clara University, UC Irvine, UCLA, NCSU, NET Institute Conference on Network Economics 2010, IIOC 2010, Mannheim Conference on Platform Markets 2010, NASM 2011, CEF 2011, and SED 2011 for their helpful comments. I thank the NET Institute and the UC Irvine Academic Senate Council on Research, Computing and Libraries (CORCL) for financial support. 
can keep her old phone number) and may have to pay an early termination fee. Similarly, when a consumer switches from one bank to another, she needs to communicate this information to all relevant parties (direct deposits, automatic payments, etc.), which is time-consuming. ${ }^{1}$ In fact, according to Shy (2001, Page 1), switching costs are one of the main characteristics of network industries. $^{2}$

Research in this area has strong policy relevance in light of regulators' interests in reducing switching costs in various network industries to increase competition. In the mobile phone industry, mobile number portability, which reduces users' switching costs by enabling them to retain their phone numbers when they switch from one network to another, was implemented in many countries in recent years (for example, see ECC (2005) for the implementation in Europe and Park (2011) for the implementation in the US). In the EU retail banking and payments systems markets, the European Competition Authorities Financial Services Subgroup recommends the implementation of switching facilities (objective and up-to-date comparison sites, switching services, etc.) and account number portability to lower switching costs (ECAFSS (2006)). In the software industry, various governments promote the adoption of open standards, such as Open Document Format for Office Applications (also known as OpenDocument or ODF), to reduce software vendor lock-in (Casson and Ryan (2006)). In predicting the effects of policies like these, we can not just rely on past research on switching costs which abstracts from network effects, because the interaction between switching costs and network effects can change the picture and make previous findings inapplicable.

Prior studies of the evolution of network industries generally make two implicit assumptions about switching costs (see, for example, Chen et al. (2009), Dubé et al. (2010), and Cabral (2011); two exceptions are Doganoglu and Grzybowski (2013) and Suleymanova and Wey (2011), discussed later in this section). First, existing consumers face infinite switching costs, therefore they stay with their (durable) products until product deaths (or until consumer deaths). ${ }^{3}$ Second, demand in each period comes from new consumers who do not face switching costs. ${ }^{4}$ The first assumption

\footnotetext{
${ }^{1}$ For PC operating systems, network effects arise from complementary application software. In the mobile phone industry, carrier-specific network effects arise from discounts for on-net calls, referred to as "tariff-mediated" network externalities in Laffont et al. (1998). In the banking industry, network effects arise from branch and ATM networks.

${ }^{2}$ On the other hand, there are industries that feature switching costs but do not have obvious network effects, such as breakfast cereal (Shum (2004)) and refrigerated orange juice and margarine (Dubé et al. (2009)).

${ }^{3}$ In fact, if the goods are non-durable and if there are no switching costs, then consumers can switch between firms costlessly in every period, and the existence of network effects will not introduce any dynamics (assuming network effects depend only on the current network size and not on the past network size).

${ }^{4}$ Mitchell and Skrzypacz (2006) consider industry dynamics with non-durable network goods and model consumers as buying products in every period. They similarly assume that consumers do not face any switching costs when they
} 
can be a reasonable approximation of durable network goods, as consumers make network choices infrequently: they typically re-optimize when their products die or when they are subject to some other events that prompt them to reconsider (such as changing jobs or moving to another area). It is then reasonable to model these events as exogenous shocks and label them collectively as stochastic "product deaths". Such an assumption is more realistic than, for example, modeling consumers as making fully-informed decisions in every period.

On the other hand, the second assumption ignores an important source of firms' demand: existing consumers who re-optimize. These consumers generally face positive but finite switching costs, and switching does occur in real-world industries. So to properly model this source of demand we need to take into account the switching costs that these consumers face.

I therefore maintain the first assumption (consumers stay with their products until the products die) but relax the second assumption to allow consumers to face switching costs when they make purchasing decisions. I develop a duopoly model of price competition with both network effects and switching costs. Firms dynamically optimize. A Markov perfect equilibrium is numerically solved for, and I investigate how switching costs affect market concentration and prices.

Here is some intuition for why it is important to take account of switching costs when studying network industries. Consider market concentration. Without switching costs, network effects tend to give rise to high market concentration: relative network size gives the larger firm an advantage, making its product more attractive to consumers, which leads to greater network size and greater advantage and propels the larger firm towards capturing most of the market. The existence of switching costs changes the dynamic. The larger firm has more locked-in consumers, and switching costs induce it to charge higher prices to "harvest" its customer base. When this effect dominates the network effect, the larger firm's size advantage tends to shrink, and therefore the market consists of similarly sized firms and does not evolve towards a "winner-take-most" structure.

Consistent with the above intuition, in this paper I find a type of dynamic equilibrium which is new to the dynamic oligopoly literature and occurs in network industries when there are high switching costs. A Peaked equilibrium is characterized by "peaceful sharing" of the market by firms focused on harvesting their own locked-in consumers: their prices peak (competition is weakest) when each firm has locked in half of the consumer population. When a size difference between the firms emerges, the smaller firm drops its price substantially to increase its expected sales and

buy. In their model, network effects depend on both the current network size and the past network size, which gives rise to dynamics in their setting. 
restore symmetric market shares in the industry. As a result of such dynamics, the industry spends most of the time in relatively symmetric states and high market concentration is unlikely - even in industries with strong network effects. By giving rise to the Peaked equilibrium in a network industry, switching costs transforms the industry from winner-take-most to peaceful sharing, bringing significant changes to market concentration and prices. This finding illustrates the importance of considering switching costs when analyzing network industries.

Furthermore, I show that the role of switching costs depends on network effects and the outside option. Absent a viable outside option (an outside good whose quality is not infinitely lower than those of the firms' products), high switching costs can neutralize the tendency towards high market concentration associated with network effects, but with a viable outside option, switching costs increase market concentration. In addition, switching costs lower prices if network effects are modest and there exists a viable outside option, but generally raise prices otherwise.

Two existing papers also study network effects and switching costs jointly. Doganoglu and Grzybowski (2013) (hereafter DG) use a two-period differentiated-products duopoly model to study the effects of switching costs and network effects. They find that regarding demand elasticities, switching costs and network effects operate in opposite directions in the first period, in that switching costs reduce demand elasticities and network effects increase them. An increase in marginal network benefits lowers prices in both periods whereas the effect of an increase in switching costs is ambiguous. They show that the first-period prices are U-shaped in switching costs and decrease when switching costs increase around zero. In comparison, in this paper I study the effects of switching costs on market concentration and prices but not their effects on demand elasticities. Furthermore, the effects I consider are based on the long-run probability distribution of the industry state, whereas DG derive results specific to each of the periods in a two-period model.

Suleymanova and Wey (2011) (hereafter SW) consider a Bertrand duopoly model with both network effects and switching costs, and find that the market outcome critically depends on the ratio of switching costs to network effects. When switching costs dominate, market sharing is the unique equilibrium. When network effects dominate, both monopoly and market sharing equilibria exist. For intermediate values of the ratio, there is a critical mass effect in that the initially dominant firm becomes a monopolist for sure if its initial installed base surpasses a critical value. A common finding of SW and this paper is that when switching costs dominate network effects, the market is shared between two similarly sized firms. For the other cases, both papers find that the market outcome depends on the interplay of the various factors in the market, such as network 
effects, switching costs, the firms' initial installed bases (in SW), and the quality of the outside option (in this paper).

The setting I consider differs from and complements those in DG and SW. I work with an infinite-horizon model (instead of one or two-period models), which allows me to investigate both short-run and long-run industry dynamics. The Peaked equilibrium is a particularly interesting finding that emerges from this setting. In addition, I endogenize the market size by modeling an outside option (instead of assuming that the market is fully covered), which enables me to analyze the competition for switching consumers in both scenarios: within a mature and saturated market, as well as when new technologies or platforms are being adopted.

At the same time, given the complexity resulting from the combination of network effects, switching costs, infinite horizon, and the existence of an outside option, I make two restrictions about consumers for tractability of the model. First, I assume that consumers are myopic and choose the good that offers the highest current utility (whereas DG assume rational expectations and SW work with fulfilled expectations Nash equilibrium). Second, I assume that in each period a single representative consumer makes a purchasing decision (whereas DG and SW model a continuum of decision-making consumers). The parsimonious specification of consumers in this paper allows rich modeling of industry dynamics and endogenous market size, at the cost of abstracting from the interesting issues of consumers' expectations and coordination, which DG and SW consider. Thus the approach and results in this paper and those in DG and SW complement each other, and together these papers allow a more comprehensive understanding of a complex market setting.

The rest of the paper is organized as follows. The next section presents the model. Section 3 reviews Markov perfect equilibria of the model. Section 4 discusses the effects of switching costs on market concentration and prices. Section 5 concludes.

\section{Model}

This section describes a dynamic model of price competition with both network effects and switching costs. The model builds on Chen et al. (2009) and adds switching costs. Since the objective is to provide some general insights about the effects of switching costs in network industries, the model is not tailored to a particular industry. Instead, a more generic model is developed to capture the key features of many markets characterized by network effects and switching costs. 


\section{$2.1 \quad$ State Space}

The model is cast in discrete time with an infinite horizon. There are two single-product pricesetting firms, who sell to a sequence of buyers with unit demands. ${ }^{5}$ Firms' products are durable subject to stochastic death. They are referred to as the inside goods. There is also an outside option ("no purchase"), indexed 0. At the beginning of a period, a firm is endowed with an installed base which represents users of its product. Let $b_{i} \in\{0,1, \ldots, M\}$ denote the installed base of firm $i$, where $M$ represents the size of the consumer population and is the upper bound on the sum of the firms' installed bases. The number of unattached consumers, $b_{0}=M-b_{1}-b_{2}$, is taken as the outside option's "installed base", though it does not offer network benefits. The industry state is $b=\left(b_{1}, b_{2}\right)$, with state space $\Omega=\left\{\left(b_{1}, b_{2}\right) \mid 0 \leq b_{i} \leq M, i=1,2 ; b_{1}+b_{2} \leq M\right\}$.

\subsection{Demand}

Demand in each period comes from a random consumer who chooses one of the three goods. Let $r \in\{0,1,2\}$ denote the good that she is loyal to. ${ }^{6}$ Let $r$ be distributed $\operatorname{Pr}(r=i \mid b)=b_{i} / M$, $i=0,1,2$, so that a larger installed base implies a larger expected demand from loyal consumers. The utility that a consumer loyal to good $r$ gets from buying good $i$ is

$$
\begin{aligned}
u_{r i} & =v_{i}+\mathbf{1}(i \neq 0) \theta g\left(b_{i}\right)-p_{i}-\mathbf{1}(r \neq 0, i \neq 0, i \neq r) k+\epsilon_{i} \\
& =\bar{u}_{r i}+\epsilon_{i}
\end{aligned}
$$

Here $v_{i}$ is the intrinsic product quality, which is fixed over time and is common across firms: $v_{i}=v, i=1,2$. Since the intrinsic quality parameters affect demand only through the expression $v-v_{0}$, without loss of generality I set $v=0$, but consider different values for $v_{0}$.

The increasing function $\theta g($.$) captures network effects, where \theta \geq 0$ is the parameter controlling the strength of network effect. There are no network effects associated with the outside option. The results reported below are based on linear network effects, that is, $g\left(b_{i}\right)=b_{i} / M$. I have also allowed $g$ to be convex, concave, and S-shaped, and the main results are robust.

\footnotetext{
${ }^{5}$ Extension to more than two firms is straightforward.

${ }^{6} \mathrm{~A}$ consumer may be loyal to a firm's product because she previously used that product and now her product dies and she returns to the market. A consumer may also be loyal to a firm's product because of her relationship with current users. For example, if a consumer is familiar with a particular product because her relatives, friends, or colleagues are users of this product, then she may be loyal to this product even if she has never purchased from this market before. In both cases, it is a reasonable approximation to model the number of loyal consumers as proportional to the size of the installed base.
} 
$p_{i}$ denotes the price for good $i$. The price of the outside option, $p_{0}$, is always zero.

The nonnegative constant $k$ denotes switching cost, and is incurred if the consumer switches from one inside good to the other. A consumer who switches from the outside option to an inside good incurs a start-up cost, which is normalized to 0 . Increasing the start-up cost above 0 has the effect of lowering the inside goods' intrinsic quality relative to that of the outside option.

$\epsilon_{i}$ is the consumer's idiosyncratic preference shock for good $i$, and $\bar{u}_{r i}$ is the utility excluding $\epsilon_{i}$. $\left(\epsilon_{0}, \epsilon_{1}, \epsilon_{2}\right)$ and $r$ are unknown to the firms when they set prices.

I assume that consumers make myopic decisions and buy the good that offers the highest current utility. Such a parsimonious specification of consumers' decision-making allows rich modeling of firms' pricing strategies and industry dynamics. In addition, I do not model consumers' multihoming (buying more than one product). Allowing the possibility of multihoming would make the model more realistic, but would impose heavy computational burden (due to a more complicated consumer decision problem and an increased dimensionality of the state space) and make the model intractable.

Assume $\epsilon_{i}, i=0,1,2$ is distributed type I extreme value, independent across products, consumers, and time. The probability that a consumer who is loyal to good $r$ buys good $i$ is then

$$
\phi_{r i}(b, p)=\frac{\exp \left(\bar{u}_{r i}\right)}{\sum_{j=0}^{2} \exp \left(\bar{u}_{r j}\right)}
$$

where $b$ is the vector of installed bases and $p$ is the vector of prices. Treating a consumer's idiosyncratic preference shocks as independent across time is admittedly a strong assumption. This way of modeling consumers' changing preferences is similar to Klemperer (1987a) and Doganoglu and Grzybowski (2013), among others. A more complicated mechanism in which the shocks are autocorrelated would be more attractive, but I was unable to incorporate such a feature while still keeping the model solvable.

\subsection{Depreciation and Transition}

In each period, each unit of a firm's installed base independently depreciates with probability $\delta \in[0,1]$, for example due to product death. Let $\Delta\left(x_{i} \mid b_{i}\right)$ denote the probability that firm $i$ 's installed base depreciates by $x_{i}$ units. We have

$$
\Delta\left(x_{i} \mid b_{i}\right)=\left(\begin{array}{c}
b_{i} \\
x_{i}
\end{array}\right) \delta^{x_{i}}(1-\delta)^{b_{i}-x_{i}}, x_{i}=0, \ldots, b_{i}
$$


as $x_{i}$ is distributed binomial with parameters $\left(b_{i}, \delta\right)$. Note that $E\left[x_{i} \mid b_{i}\right]=b_{i} \delta$, therefore the expected size of the depreciation to a firm's installed base is proportional to the size of that installed base. When the firms' installed bases depreciate, the number of unattached consumers, $b_{0}=M-b_{1}-b_{2}$, goes up by the same number as the aggregate depreciation, and the total market size is fixed (at $M)$.

Let $q_{i} \in\{0,1\}$ indicate whether or not firm $i$ makes the sale. Firm $i$ 's installed base changes according to the transition function

$$
\operatorname{Pr}\left(b_{i}^{\prime} \mid b_{i}, q_{i}\right)=\Delta\left(b_{i}+q_{i}-b_{i}^{\prime} \mid b_{i}\right), b_{i}^{\prime}=q_{i}, \ldots, b_{i}+q_{i} .
$$

If the joint outcome of the depreciation and the sale results in an industry state outside of the state space, the probability that would be assigned to that state is given to the nearest state(s) on the boundary of the state space.

\subsection{Timing and Information of the Model}

At the beginning of a period, the firms are endowed with installed bases $b=\left(b_{1}, b_{2}\right)$. Depreciation then takes place according to Eq. (2). Next the firms set prices without knowing the decisionmaking consumer's idiosyncratic preference shocks and the good that she is loyal to (therefore the firms can not price discriminate), though the firms do know the probability distributions. The consumer then chooses one of the three goods, based on (1) the installed bases before the depreciation, (2) the firms' prices, (3) the realization of the good that she is loyal to, and (4) the realization of her idiosyncratic preference shocks. Lastly the next-period state $b^{\prime}$ is determined according to the transition function Eq. (3).

Note that when the consumer makes her choice, the network effects are based on the installed bases at the beginning of the period, that is, before the depreciation and before this consumer is added to any of the networks. One motivation for this specification is that network effects often appear with a lag, as is the case with software applications, video game titles, etc. A lag is created when a network good leads to the creation over time of a complementary stock that increases the value of the network (Llobet and Manove (2006)). For example, a computer operating system induces the development of a complementary stock of software applications, and since the development of these software applications takes time, the size of the complementary stock is proportional to the size of the installed base with a lag. 


\subsection{Bellman Equation and Strategies}

Let $V_{i}(b)$ denote the expected net present value of future cash flows to firm $i$ in state $b$. Firm $i$ 's Bellman equation is

$$
V_{i}(b)=\max _{p_{i}} E_{r}\left[\phi_{r i}\left(b, p_{i}, p_{-i}(b)\right) p_{i}+\beta \sum_{j=0}^{2} \phi_{r j}\left(b, p_{i}, p_{-i}(b)\right) \bar{V}_{i j}(b)\right]
$$

where $p_{-i}(b)$ are the prices charged by firm $i$ 's rivals in equilibrium (given the installed bases), the (constant) marginal cost of production is normalized to zero, $\beta \in[0,1)$ is the discount factor, and $\bar{V}_{i j}(b)$ is the expected continuation value to firm $i$ given that firm $j$ wins the current consumer:

$$
\bar{V}_{i j}(b)=\sum_{b^{\prime}} \operatorname{Pr}\left(b^{\prime} \mid b, q_{j}=1\right) V_{i}^{\prime}\left(b^{\prime}\right)
$$

Differentiating the right-hand side of Eq. (4) with respect to $p_{i}$ and using the properties of logit demand yields the first-order condition ${ }^{7}$

$$
E_{r}\left[-\phi_{r i}\left(1-\phi_{r i}\right)\left(p_{i}+\beta \bar{V}_{i i}\right)+\phi_{r i}+\beta \phi_{r i} \sum_{j \neq i} \phi_{r j} \bar{V}_{i j}\right]=0
$$

The pricing strategies $p(b)$ are the solution to the system of first-order conditions.

\subsection{Parameterization}

The key parameters of the model are the strength of network effect $\theta$, the switching cost $k$, the rate of depreciation $\delta$, and the quality of the outside option $v_{0}$. I focus on two values for $v_{0}$, $-\infty$ (fixed market size) and 0 (endogenous market size), but also consider in-between values. The lower bound for $\delta$ is zero and corresponds to the unrealistic case in which installed bases never depreciate. On the other hand, if $\delta$ is sufficiently high then the industry never takes off. I consider $\delta \in\{0.04,0.05,0.06,0.07\}$ (Appendices 2 and 3 report the results for a broader range of $\delta$ values, $\delta \in\{0.04,0.05, \ldots, 0.1\})$. I investigate the following values for the strength of network effect and the switching cost: $\theta \in\{0,0.2, \ldots, 4\}$, and $k \in\{0,0.2, \ldots, 3\}$. I set $M=20$ and $\beta=\frac{1}{1.05}$ (which corresponds to a yearly interest rate of $5 \%$ ) in the baseline specification.

While the model is not intended to fit any specific product, the own-price elasticities for the

\footnotetext{
${ }^{7}$ See Appendix 1 for the derivation of the first-order condition.
} 
parameterizations that I consider, ranging from -1.55 to -0.40 , are in line with those reported in empirical studies, such as Gandal et al. (2000) (-0.54 for CD players, computed according to results reported in the paper), Dranove and Gandal (2003) ( -1.20 for DVD players), and Clements and Ohashi (2005) (ranging from -2.15 to -0.18 for video game consoles).

In this model, in each period a single representative consumer makes a purchasing decision, which means the speed with which the smaller firm can possibly catch up is limited. I was unable to incorporate into the current framework several consumers or a continuum of consumers making purchasing decisions in each period, as doing so adds substantial computational burden (especially due to multiple coordination equilibria) to an already complex model. Nevertheless, I run additional parameterizations to assess how much the results might depend on the built-in inertia resulting from the single decision-making consumer assumption. Specifically, I reduce the value of $M$ from 20 to 16,12 , and 8 and re-compute the equilibrium. When $M$ is decreased, the speed with which the smaller firm can possibly catch up is increased and the built-in inertia is lessened. I find that the main findings, including the types of dynamic equilibria and the qualitative effects of switching costs on market concentration and prices, are robust to decreasing the value of $M$ (results are available from the author upon request).

\section{Dynamic Equilibrium}

In this section, I first discuss the equilibrium concept, then present the different types of dynamic equilibrium of the model.

\subsection{Equilibrium}

I focus attention on symmetric Markov perfect equilibria (MPE), where symmetry means agents with identical states are required to behave identically. For example, if there are two firms, then symmetry means firm 2's price in state $\left(b_{1}, b_{2}\right)=(\widehat{b}, \widetilde{b})$ is identical to firm 1's price in state $\left(b_{1}, b_{2}\right)=$ $(\widetilde{b}, \widehat{b})$, and similarly for the value function. I therefore define $p\left(b_{1}, b_{2}\right) \equiv p_{1}\left(b_{1}, b_{2}\right)$ and $V\left(b_{1}, b_{2}\right) \equiv$ $V_{1}\left(b_{1}, b_{2}\right)$, and note that $p_{2}\left(b_{1}=\widehat{b}, b_{2}=\widetilde{b}\right)=p(\widetilde{b}, \widehat{b})$ and $V_{2}\left(b_{1}=\widehat{b}, b_{2}=\widetilde{b}\right)=V(\widetilde{b}, \widehat{b})$.

I restrict attention to pure strategies, which follows the majority of the literature on numerically solving dynamic stochastic games (Pakes and McGuire (1994), Pakes and McGuire (2001)). A symmetric MPE in pure strategies exists, as the model satisfies the assumptions in Doraszelski and Satterthwaite (2010) that guarantee the existence of such an equilibrium: the model's primitives are bounded (the state space is finite, profits are bounded, and firms discount future payoffs), 
the transition function depends continuously on firms' actions (prices), firms' best reply sets are single-valued, and the profit functions and the transition function are symmetric.

As is true with many other dynamic models, there may exist multiple MPE. I therefore take a widely used equilibrium selection rule in the dynamic games literature by computing the limit of a finite-horizon game as the horizon grows to infinity (for details see Chen et al. (2009)).

Depending on the parameter values, three qualitatively distinct equilibria are found. They are referred to as Rising, Tipping, and Peaked.

A Rising equilibrium is characterized by a relatively monotonic policy function, in which price increases in a firm's own base and is insensitive to the rival's base. The industry spends most of the time in symmetric states. This equilibrium occurs when both network effect and switching cost are weak. ${ }^{8}$

With non-trivial network effect and/or switching cost, two types of equilibria dominate: Tipping and Peaked. These equilibria are the most insightful for learning about dynamic competition and the role of switching costs, and will be the focus of our attention.

\subsection{Tipping Equilibrium}

In a Tipping equilibrium, there is intense price competition when firms' installed bases are of comparable size, and the industry spends most of the time in asymmetric states. A Tipping equilibrium occurs when the network effect is strong and depreciation is modest. This equilibrium is also found in prior dynamic models with increasing returns, such as Doraszelski and Markovich (2007), Chen et al. (2009), and Besanko et al. (2010).

An example of a Tipping equilibrium is shown in Figure 1. ${ }^{9}$ The policy function features a deep trench along and around the diagonal (Panel 1). When the industry is sufficiently away from the diagonal, price is relatively high. The value function (Panel 2) shows that the larger firm enjoys a much higher value than the smaller firm. It is the substantial difference between the leader's and the follower's values that drives the intense price competition in symmetric states. Each firm prices aggressively (charges low prices) in hope of getting an installed base advantage and eventually capturing most of the market; hence the deep trench along and around the diagonal in the policy function.

\footnotetext{
${ }^{8}$ When both network effect and switching cost are 0 , the model degenerates to a static one and the price function is flat.

${ }^{9}$ Each of Figures 1 and 2 plots the equilibrium results for just one representative parameterization. The parameter values under which each type of equilibrium occurs are described in more details in Subsection 4.1 below.
} 
When the industry is sufficiently away from the diagonal, the smaller firm gives up the fight by not pricing aggressively, and accepts having a low market share. If instead it were to price aggressively and try to overtake the larger firm, it would have to price at a substantial discount for an extended period of time. Anticipating that such an aggressive strategy is not profitable, the smaller firm abandons the fight, ensuring that the larger firm captures most of the market and enjoys high profits.

To show the evolution of the industry structure over time, Panels 3 and 4 plot the 15-period transient distribution of installed bases (which gives the probability with which the industry state takes a particular value after 15 periods, starting from state $(0,0)$ in period 0$)$ and the limiting distribution (which gives the probability with which the state takes a particular value as the number of periods approaches infinity), respectively. Both the transient distribution and the limiting distribution have modes that are highly asymmetric. They show that over time the industry state moves towards asymmetric outcomes, and that high market concentration is likely.

Panel 5 plots the probability that a firm makes a sale. The larger firm enjoys a significant advantage: the average probability that firm 1 makes a sale is 0.71 in states with $b_{1} \geq b_{2}$, compared to an average probability of 0.29 in states with $b_{1} \leq b_{2}$.

Panel 6 plots the resultant forces, which report the expected movement of the state from one period to the next (for visibility of the arrows, the lengths of all arrows are normalized to 1, therefore only the direction, not the magnitude, of the expected movement is reported). The advantage enjoyed by the larger firm in terms of the sale probability pulls the industry away from the diagonal once a small asymmetry arises. Such dynamics are responsible for the tipping of the market that leads to asymmetric outcomes in the long run.

Result 1 (Tipping Equilibrium). When the network effect is strong and depreciation is modest, equilibrium is characterized by intense price competition when firms have comparable installed bases, and tipping towards high market concentration when an asymmetry emerges.

When there exists a viable outside option (an outside good whose quality is not infinitely lower than those of the firms' products), there is a variant to Tipping equilibrium. In this variant, referred to as Mild Tipping equilibrium, the modes of the limiting distribution are still highly asymmetric but a fair amount of mass is spread over the states between the two modes. With a viable outside option, the payoff to capturing the market is reduced, because the outside option serves as a nonstrategic player and restrains the firm's ability to exploit its locked-in consumers. Consequently, 
in a Mild Tipping equilibrium, firms do not fight so fiercely for market share when they are of comparable size, and the tendency for the industry to move towards asymmetric states is weaker than in a Tipping equilibrium.

\subsection{Peaked Equilibrium}

There is another type of equilibrium which is new to the dynamic oligopoly literature and arises solely because firms also compete for existing consumers who face switching costs. A Peaked equilibrium is characterized by a peak in the policy function when each firm has half of the consumer population in its installed base. Away from this peak, the smaller firm's price drops rapidly; the larger firm's price also drops but by a smaller amount. The industry spends most of the time in relatively symmetric states and high market concentration is unlikely. A Peaked equilibrium occurs when the switching cost is strong and there does not exist a viable outside option.

An example of a Peaked equilibrium is shown in Figure 2 (the only change in the parameterization from Figure 1 to Figure 2 is that $k$ is increased from 1 to 2 ). When each firm has locked in half of the consumer population, price competition is weak as reflected in the peak in the policy function (Panel 1). Due to switching costs, both firms have strong incentives to charge high prices to "harvest" their large bases of locked-in consumers. Moreover, the absence of unattached consumers (consumers who are not loyal to either firm) weakens firms' "investment" incentive to lower prices. Off of the peak, the smaller firm drops its price substantially to increase expected sales and move the industry back to the peak. The larger firm also drops its price in response to the smaller firm's aggressive pricing.

The value function (Panel 2) also has a peak when each firm locks in half of the consumer population. Off of the peak, the smaller firm's value drops rapidly. The larger firm's value also drops slightly, because the smaller firm starts to price aggressively and the larger firm has to respond by cutting its own price. Since firms have little incentive to induce tipping in their favor, high market concentration is unlikely, as reflected in the unimodal transient distribution and limiting distribution (Panels 3 and 4, respectively).

Panel 5 shows that in states that are reasonably symmetric, it is the smaller firm who has a higher probability of sale. This pattern results from the smaller firm's aggressive pricing aimed at bringing the industry back to the peak. In Panel 6, the resultant forces show global convergence towards the symmetric modal state.

The occurrence of a Peaked equilibrium requires strong switching cost and the absence of a 
viable outside option. A key function of switching costs is that they segment the market into submarkets, each containing consumers who have previously purchased from a particular firm. A Peaked equilibrium is based on such market segmentation, which allows firms to price in a fashion that resembles collusion even in a noncooperative environment (see Klemperer (1987b)). However, if there exists a viable outside option, then it constitutes a non-strategic player and restrains firms' ability to exploit the locked-in consumers, weakening the basis for firms to engage in collusion-like pricing. In fact, with $v_{0}=0$ a Peaked equilibrium never occurs. We further investigate the role of the outside option in the next section.

Result 2 (Peaked Equilibrium). When the switching cost is strong and there does not exist a viable outside option, equilibrium is characterized by a peak in the prices when each firm locks in half of the consumer population, and an absence of high market concentration.

The Peaked equilibrium identified above is new to the dynamic oligopoly literature, and is consistent with some real-world examples. For instance, Barla (2000) finds that in the U.S. domestic airline industry (with switching costs due to frequent-flyer programs), prices are higher when firms have symmetric market shares. While the hypothesis in the theoretical literature has been that symmetry among firms facilitates collusion (for example, Compte et al. (2002) and Vasconcelos (2005)), the Peaked equilibrium suggests a new possibility, in which switching costs and the lack of a viable outside option induce firms in a noncooperative environment to heighten prices when the market is evenly segmented.

Furthermore, to the extent that firms are able to choose switching costs, they can use switching costs to collude tacitly on the Peaked equilibrium. Therefore, the finding here is not so much in contrast to the collusion explanation, once we consider tacit collusion and allow switching costs to be endogenous. ${ }^{10}$

\subsection{Industry Dynamics}

The current model allows us to study strategic interactions between endogenously asymmetric firms in a general dynamic setting. Below we examine how the industry structure and the firms' strategic choices evolve over time, focusing on the contrast between Tipping equilibrium and Peaked equilibrium.

\footnotetext{
${ }^{10} \mathrm{I}$ thank a referee for suggesting this interpretation.
} 
The left column of Figure 3 depicts a Tipping equilibrium $\left(\left(v_{0}, \delta, \theta, k\right)=(-\infty, 0.06,2.2,1)\right)$. From top to bottom, the four panels plot the evolution of the firms' installed bases, prices, probabilities of sale, and profits, respectively, from period 0 to period 100 , starting from state $(0,0)$ in period 0 . The solid lines show the expectation (based on transient distributions) of the variables for the larger firm, and the dashed lines show those for the smaller firm. The right column plots the same for a Peaked equilibrium $\left(\left(v_{0}, \delta, \theta, k\right)=(-\infty, 0.06,2.2,2)\right)$. For the purpose of comparison, the scale and location of the $y$-axis are the same for panels in the same row.

The two columns exemplify the distinction between Tipping equilibrium and Peaked equilibrium in terms of firms' endogenous asymmetry and strategic interactions over time. In Tipping equilibrium, the difference in firms' installed bases widens quickly, reaching 4.6 by period 10 and stabilizing at 7.4 in the long run (Panel 1). In contrast, in Peaked equilibrium, the difference in firms' installed bases grows slowly over time and remains below 2.9 throughout (Panel 2). In the long run, the larger firm's base is larger than the smaller firm's by $169 \%$ in Tipping equilibrium, but by only $43 \%$ in Peaked equilibrium, indicating that the tendency towards high market concentration is much stronger in Tipping equilibrium.

Turning to firms' pricing decisions, we see that in Tipping Equilibrium (Panel 3), at the beginning of the race the firms fiercely fight for market share by charging negative prices. ${ }^{11}$ When a firm pulls ahead, both firms increase their prices substantially. The larger firm keeps its price below its rival's until period 25 (in which the base differential reaches 6.5). ${ }^{12}$ Afterwards the larger firm's price is slightly higher than the smaller firm's, but the price differential is never larger than 0.17. On the other hand, in Peaked equilibrium (Panel 4), the firms' prices start at about 1 and increase over time. The larger firm's price is always higher than the smaller firm's, and the price differential gradually widens until it stabilizes at 0.93 , much larger than the price differential in Tipping equilibrium. Furthermore, both firms' prices are much higher in the Peaked equilibrium than in the Tipping equilibrium.

Next we consider firms' probabilities of sale. In Tipping equilibrium (Panel 5), the larger firm enjoys a much larger probability of sale throughout, and in the long run, the larger firm makes a

\footnotetext{
${ }^{11}$ As mentioned in the Model section, this model does not allow consumers' multihoming, therefore a consumer can not buy more than one product to take advantage of the negative prices.

${ }^{12}$ In the early stages of the market the installed base differential emerges and quickly widens but the larger firm has not yet captured most of the market. Therefore the larger firm prices more aggressively in the hope of building on its installed base advantage and eventually capturing most of the market, whereas the smaller firm finds it best to price less aggressively and accept having a low market share (see the discussion in Subsection 3.2). As a result of this difference in the firms' pricing incentives, the larger firm charges a lower price than the smaller firm in the early stages of the market.
} 
sale with probability 0.71 , compared to only 0.29 for the smaller firm. This is in sharp contrast to Peaked equilibrium (Panel 6). There, the two firms' probabilities of sale are never more than 0.06 apart. The larger firm holds a slight lead initially, but the smaller firm is on top afterwards. This pattern is a result of the market segmentation created by switching costs, which induces the firms to share the market and exploit their locked-in consumers and discourages the larger firm from pricing aggressively to enlarge its market share.

As for profits, in Tipping equilibrium (Panel 7), we see that both firms have negative profits at the beginning of the race as they fight to capture the market. When the race is over, the larger firm enjoys a much higher profit than the smaller firm (the larger firm's long-run profit is 1.10, compared to 0.39 for the smaller firm). In contrast, in Peaked equilibrium (Panel 8), each firm's profit starts at about 0.5 and gradually increases. The larger firm always leads in profit, but not by much (the larger firm's long-run profit is 1.43 , compared to 1.12 for the smaller firm).

The only difference between the parameterizations in the two columns in Figure 3 is an increase in the switching cost from $k=1$ in the left column to $k=2$ in the right column. Therefore, the contrast described above is an example of switching costs' ability to drastically change industry dynamics. Here an increase in switching costs suppresses the fierce competition to capture the market that is characteristic of network industries and turns it into a "peaceful sharing" of the market by two firms focused on harvesting their own locked-in consumers. ${ }^{13}$

\section{The Effects of Switching Costs in Network Industries}

In this section, I first discuss the multiple effects of switching costs on firms' pricing and expected sales, which lays the groundwork for understanding the results that follow, about how switching costs affect market concentration and prices in equilibrium.

First, when considered alone (without network effects), switching costs induce the larger firm to charge higher prices to "harvest" its customer base, since the larger firm has more locked-in consumers than the smaller firm. As a result, the larger firm tends to lose consumers to the smaller firm. This is the fat cat effect of switching costs, with the larger firm being a nonaggressive fat cat. This effect works against market concentration and therefore markets with switching costs but not network effects tend to be stable (Beggs and Klemperer (1992), Chen and Rosenthal (1996), Taylor

\footnotetext{
${ }^{13}$ Budd et al. (1993) study in an abstract model of dynamic duopoly whether the larger firm is likely to become increasingly dominant. They similarly note that switching costs, by making price cuts more costly for the larger firm than for the smaller firm, may be able to overcome the gravitation towards asymmetric market shares in their setting and result in a "catch-up" equilibrium.
} 
(2003)).

Second, when we incorporate network effects into the analysis, switching costs reinforce network effects by heightening the exit barrier for locked-in consumers, which solidifies existing networks and makes a network size advantage longer-lasting. This is the network solidifying effect of switching costs, which tends to benefit the larger firm and increase market concentration.

Third, given the network solidifying effect described above, switching costs can also induce the larger firm to price more aggressively. By making a network size advantage longer-lasting and hence more valuable, an increase in switching costs strengthens the larger firm's incentive to price aggressively in order to enlarge its market share, since the prospect of capturing the market becomes better and the reward becomes bigger. This is the top dog effect of switching costs, with the larger firm being an aggressive top dog. This effect complements network effects and facilitates tipping towards high market concentration. ${ }^{14}$

Fourth, when there exists a viable outside option so that the market size is endogenous, switching costs also have a market contraction effect, in that an increase in switching costs shifts demand from the inside goods to the outside option, shrinking the market served by the firms. Recall that the switching cost is incurred when a consumer switches from one inside good to the other. Therefore an increase in the switching cost does not affect the choice probabilities of an unattached consumer (a consumer who is not royal to either firm). For a consumer who is loyal to, for example firm 1, an increase in the switching cost makes firm 2's product less attractive to her, so it reduces her choice probability for firm 2's product while increasing her choice probabilities for firm 1's product and the outside option. Thus when we aggregate across the three types of consumers (unattached, loyal to firm 1, and loyal to firm 2), an increase in the switching cost increases the overall choice probability for the outside option.

\subsection{Switching Costs and Market Concentration}

For the primary dynamic forces of the model to be at work, the relevant part of the parameter space is where the rate of depreciation is neither too low (so that there is customer turnover) nor too high (so that the investment incentive is not weak). In that part of the parameter space, the switching cost and its interaction with the network effect have significant impact on market concentration.

\footnotetext{
${ }^{14}$ The terms "fat cat effect" and "top dog strategy" are introduced by Fudenberg and Tirole (1984) in the context of strategic investment and entry deterrence/accommodation.
} 


\subsubsection{Fixed Market Size}

First consider the case with fixed market size $\left(v_{0}=-\infty\right)$. Here, two forces compete against each other: the fat cat effect, which works against market concentration, and the combination of the network solidifying effect and the top dog effect, which increases market concentration. Results from the model indicate that in industries with significant network effects, the network solidifying effect and the top dog effect dominate at low switching cost but the fat cat effect takes over at high switching cost.

For example, the top row of panels in Figure 4 plot the expected HHI for $v_{0}=-\infty$ and $\delta=0.05,0.06$, and 0.07, respectively. Each panel reports the HHI for the parameterizations with $\theta \in\{0,0.2, \ldots, 4\}$ and $k \in\{0,0.2, \ldots, 3\}$. These panels show that when the network effect is weak, the HHI is low throughout and declines slightly as the switching cost is increased. The equilibrium morphs from Rising equilibrium at low switching cost to Peaked equilibrium at high switching cost.

In contrast, when the network effect is strong $(\theta \geq 2$ in Panel $1, \theta \geq 2.4$ in Panel 2 , and $\theta \geq 2.8$ in Panel 3), the HHI starts with a relatively high level at $k=0$. As the switching cost increases, the HHI initially increases but later drops significantly. For example, with $\delta=0.06$ (Panel 2) and $\theta=3$, the HHI starts with 0.645 at $k=0$, increases to 0.664 at $k=1$, then decreases to 0.647 at $k=1.6$ before plummeting to 0.544 at $k=1.8$. It then continues to decrease slightly, reaching 0.520 at $k=3$. A Tipping equilibrium occurs for $k \leq 1.6$ and a Peaked equilibrium occurs for $k>1.6$. These results show that high switching costs can neutralize the tendency towards high market concentration associated with network effects, by inducing the larger firm to act as a nonaggressive fat cat rather than pricing aggressively to build on its installed base advantage.

For some intermediate values of the network effect, the gradual increase in the switching cost causes the equilibrium to change from Rising to Tipping then to Peaked. For example, with $\delta=0.06$ (Panel 2) and $\theta=2.2$, there is a Rising equilibrium at $k=0(\mathrm{HHI}=0.561)$, a Tipping equilibrium at $k=1(\mathrm{HHI}=0.627$; depicted in Figure 1$)$, and a Peaked equilibrium at $k=2(\mathrm{HHI}=0.527$; depicted in Figure 2).

\subsubsection{Endogenous Market Size}

When there exists a viable outside option, it constitutes a non-strategic player and restrains firms' ability to harvest their locked-in consumers, because these consumers can resort to the outside option if prices charged by the firms are too high. Such a "threat" generated by the outside option diminishes the fat cat effect, letting the combination of the top dog effect and the network solidifying 
effect dominate the fat cat effect. Consistent with this, results from the model show that with a viable outside option, an increase in switching costs increases market concentration. For example, the bottom row of panels in Figure 4 plot the expected HHI for $v_{0}=0$ and $\delta=0.05,0.06$, and 0.07 , respectively. In contrast to the top row, in the bottom row the HHI always increases in the switching cost. There is a Rising equilibrium when the network effect is weak and a Tipping or Mild Tipping equilibrium when the network effect is strong. An increase in the switching cost does not change the type of equilibrium that occurs; instead, it results in the limiting distribution putting more mass in asymmetric states and states close to the origin.

Result 3 (Switching Costs and Market Concentration). Without a viable outside option, if the network effect is weak, then the HHI is low and an increase in the switching cost causes the HHI to decline slightly; but if the network effect is strong, then an increase in the switching cost first raises the already elevated HHI and then causes it to drop sharply. With a viable outside option, an increase in the switching cost raises the HHI.

\subsection{Switching Costs and Prices}

In this subsection we consider the effects of switching costs on prices in network industries. Figure 5 plots the average price (weighted by expected sales and probabilities in the limiting distribution) against the switching cost, with $\delta=0.06$. In the left column of panels $v_{0}=-\infty$, and in the right column $v_{0}=0$. From the top row to the bottom row, $\theta$ is $0,1,2,3,4$, respectively. The figure reveals the following patterns. First, without a viable outside option $\left(v_{0}=-\infty\right)$, the average price mostly increases in the switching cost (the left column). ${ }^{15}$ Second, with a viable outside option $\left(v_{0}=0\right)$, the average price decreases in the switching cost when the network effect is modest (Panels 2, 4, and 6) and increases in the switching cost when the network effect is strong (Panel 10). Results from a broad set of parameterizations confirm these patterns and are reported in Appendix 2.

\subsubsection{The Outside Option}

To understand the above patterns, we start by considering the market contraction effect of switching costs. Examination of the policy functions for all the parameterizations described in Subsection

\footnotetext{
${ }^{15}$ An exception is that without a viable outside option, for zero to modest network effects $(\theta \leq 2)$ and small switching costs $(k<0.5)$, average price first slightly decreases in the switching cost before starting to increase. For example, when $\theta=0$ (Panel 1 in Figure 5), average price starts with 2.00 at $k=0$, drops slightly to 1.95 at $k=0.4$, then gradually increases to 4.33 at $k=3$. This pattern is consistent with the U-shape relationship between prices and switching costs found in Cabral (2008), Doganoglu (2010), and Viard (2007), who study switching costs without network effects or outside option.
} 
2.6 with $v_{0} \in\{-2,0\}$ shows that a contraction movement of the state (a movement parallel to the $(0,0)-(20,20)$ diagonal and in the direction of decreasing market size) causes the average price to decrease. The intuition is that a contraction movement represents a reduction in the firms' installed bases (network sizes), and the firms find it optimal to lower their prices in response to their products becoming less attractive (relative to the outside option). Therefore, the market contraction effect, which causes contraction movements of the state, reduces the average price. The operation of the market contraction effect depends on the existence of a viable outside option. As the quality of the outside option $v_{0}$ increases, the market contraction effect is strengthened, making it more likely that an increase in the switching cost will cause the average price to drop.

\subsubsection{Strength of the Network Effect}

Next considering the network solidifying effect of switching costs. Examination of the policy functions for all the parameterizations described in Subsection 2.6 with $\theta>0$ shows that an asymmetry movement of the state (a movement parallel to the $(0,20)-(20,0)$ diagonal and in the direction of increasing asymmetry) causes the average price to increase except when there is a Peaked equilibrium (for an example of the latter see Panel 1 in Figure 2). An asymmetry movement represents a widening of the installed base differential between the two firms, which allows the larger firm to charge a higher price and drives up the average price - except when there is a Peaked equilibrium, in which case both firms drop their prices when the state moves away from the symmetric peak. Therefore, the network solidifying effect, which generally causes asymmetry movements of the state, increases the average price except when there is a Peaked equilibrium.

The above discussion sheds light on how the relationship between switching costs and prices depends on the strength of network effects, when there exists a viable outside option. The intuition is as follows. With a viable outside option, Peaked equilibrium disappears, and therefore asymmetry movements of the industry state raise the average price. Under this circumstance, a stronger network effect amplifies the network solidifying effect to make it more likely that the average price will increase in the switching cost. The amplification happens in the following two steps.

First, the basic function of the network solidifying effect is that it gives the larger firm an extra advantage by making the installed base differential longer-lasting. At the same time, the fundamental property of network effects is that they create a "snowball" effect that allows a small base differential to quickly widen. Therefore, a stronger network effect amplifies the extra advantage for the larger firm created by the network solidifying effect and induces the larger firm to price even 
more aggressively as a "top dog" (recall that the top dog effect is based on the network solidifying effect), thus giving rise to a larger increase in the asymmetry in the industry.

Second, a stronger network effect translates an installed base differential into a larger quality differential and allows the larger firm to raise its price more substantially. To illustrate, Figure 6 plots the policy functions for two parameterizations that differ only in $\theta: \theta=1$ in Panel 1 and $\theta=3$ in Panel 2. The biggest difference between the two policy functions is that as a firm gains an installed base advantage over its rival, its price increases only mildly in Panel 1 but significantly in Panel 2. For instance, when the state moves parallel to the $(0,20)-(20,0)$ diagonal from $(8,8)$ to $(14,2)$, in Panel 1 firm 1's price increases only $7.1 \%$ from 1.19 to 1.27 , whereas in Panel 2 its price increases a sizeable $59.4 \%$ from 0.86 to 1.37 . Therefore, when the network solidifying effect and the top dog effect pull the industry towards asymmetric states, a stronger network effect translates such asymmetry movements into more substantial price increases by the larger firm, making it more likely that the overall impact of the switching cost on the average price is positive.

Result 4 (Switching Costs and Prices). Without a viable outside option, the average price mostly increases in the switching cost. With a viable outside option, if the network effect is modest then the average price decreases in the switching cost, but if the network effect is strong then the average price increases in the switching cost.

\subsection{Additional Results}

Regarding the welfare effects of switching costs, I find that they reduce consumer surplus, but their effect on producer surplus is ambiguous. Switching costs benefit the firms when there does not exist a viable outside option, but become more and more harmful to the firms as the quality of the outside option increases. Moreover, a stronger network effect makes it more likely that the firms will benefit from switching costs. These results again show that the outside option and the network effect are important determinants of the effects of switching costs. Detailed results are reported in Appendix 3.

In the model in this paper, firms can not "target" switchers by offering a different price specifically for them. This fits the reality in industries in which firms can not price discriminate. In some industries, such as mobile phone and television subscriptions, firms can and do "pay consumers to switch", by making special offers to their rival firms' customers. Although fully endogenizing firms' pricing strategies targeting switchers is beyond the scope of this paper, based on the current framework, in Appendix 4 I consider a scenario in which firms subsidize switchers by paying them 
a fixed portion of the switching cost.

The main intuition for the impact of such switching cost subsidy is that it partially offsets switching costs, and therefore reduces the effectiveness of switching costs in changing industry dynamics and the market outcome. The results from the model are consistent with this intuition. We see that as a consequence of the switching cost subsidy, it now takes a larger switching cost to transform the market equilibrium from Tipping to Peaked. For example, as we increase the switching $\operatorname{cost} k$ while holding $v_{0}=-\infty, \delta=0.06$, and $\theta=2.2$, the shift of the market equilibrium from Tipping to Peaked occurs around $k=1.2$ if the switcher bears the entire switching cost, but if the switching cost is split evenly between the firm and the switcher, the shift occurs later, around $k=3.2$. See Appendix 4 for more details.

\section{Conclusion}

In this paper I investigate the effects of switching costs on the dynamics and market outcome in network industries using a dynamic model of price competition with both network effects and switching costs. I find a type of equilibrium which is new to the dynamic oligopoly literature. A Peaked equilibrium occurs when there are high switching costs and is characterized by "peaceful sharing" of the market by firms focused on harvesting their own locked-in consumers: their prices peak (competition is weakest) when each firm has locked in half of the consumer population. By giving rise to the Peaked equilibrium in a network industry, switching costs transforms the industry from winner-take-most to peaceful sharing, bringing significant changes to market concentration and prices.

I provide a series of results that characterize the effects of switching costs on market concentration and prices, summarized in Table 1. These results show that the role of switching costs critically depends on the strength of network effects and the quality of the outside option. Without a viable outside option, high switching costs can neutralize the tendency towards high market concentration associated with network effects, but with a viable outside option, switching costs increase market concentration. Furthermore, switching costs lower prices if network effects are modest and there exists a viable outside option, but generally raise prices otherwise.

These results provide testable predictions that can be brought to the data in real-world industries with various combinations of network effects, switching costs, and outside options. For example, industries with high network effects and high switching costs include computer operating systems and video game consoles; industries with high network effects and low switching costs in- 
clude mobile phone networks (after the implementation of mobile number portability) and online social networks; and industries with low network effects and high switching costs include online banking and airlines' frequent-flyer programs. In mature and saturated markets such as mobile phone networks, there does not exist a viable outside option, whereas for new technologies or platforms being adopted by consumers, such as online social networks, "doing without" is often a viable outside option.

Research in this area has strong policy relevance in light of regulators' interests in public policies that reduce switching costs in network industries, such as mobile number portability in the mobile phone industry, account number portability in the banking industry, and the adoption of open standards in the software industry, as described in the Introduction. Existing empirical studies on the effects of such policies provide evidence that supports the findings in this paper. For example, the implementation of mobile number portability is found to decrease the prices (Shi et al. (2006) and Park (2011)) and increase the market concentration (Shi et al. (2006)) in the mobile phone industry. Since the mobile phone industry has carrier-specific network effects (arising from discounts for on-net calls) and does not have a viable outside option, these empirical findings are consistent with the predictions from my model.

Finally, in this paper I have had to make some simplifying assumptions to facilitate the computation. On the demand side, consumers are myopic and choose the good that offers the highest current utility. On the supply side, qualities of the products are exogenous and firms compete in prices but not in qualities. Relaxing these assumptions in future research will prove useful. Nevertheless, one unambiguous lesson we learn from the current analysis is that effective policy-making in network industries must pay attention to switching costs and their interactions with network effects and the outside option, which are shown to have critical influence on industry dynamics and the market outcome.

\section{References}

Barla, P. (2000). Firm size inequality and market power. International Journal of Industrial Organization 18, 693-722.

Beggs, A. and P. Klemperer (1992). Multi-Period Competition with Switching Costs. Econometrica $60(3), 651-666$. 
Besanko, D., U. Doraszelski, Y. Kryukov, and M. Satterthwaite (2010). Learning-by-Doing, Organizational Forgetting, and Industry Dynamics. Econometrica 78(2), 453-508.

Budd, C., C. Harris, and J. Vickers (1993). A Model of the Evolution of Duopoly: Does the Asymmetry between Firms Tend to Increase or Decrease? Review of Economic Studies 60, $543-573$.

Cabral, L. (2008). Switching Costs and Equilibrium Prices. New York University.

Cabral, L. (2011). Dynamic Price Competition with Network Effects. Review of Economic Studies $78,83-111$.

Casson, T. and P. S. Ryan (2006). Open Standards, Open Source Adoption in the Public Sector, and Their Relationship to Microsoft's Market Dominance. In S. Bolin (Ed.), Standards Edge: Unifier or Divider?, pp. 87-99. Sheridan Books.

Chen, J., U. Doraszelski, and J. Harrington (2009). Avoiding Market Dominance: Product Compatibility in Markets with Network Effects. RAND Journal of Economics 40(3), 455-485.

Chen, Y. and R. Rosenthal (1996). Dynamic duopoly with slowly changing customer loyalties. International Journal of Industrial Organization 14, 269-296.

Clements, M. and H. Ohashi (2005). Indirect Network Effects and the Product Cycle: U.S. Video Games, 1994 - 2002. Journal of Industrial Economics 53, 515-542.

Compte, O., F. Jenny, and P. Rey (2002). Capacity constraints, mergers and collusion. European Economic Review 46, 1-29.

Doganoglu, T. (2010). Switching Costs, Experience Goods and Dynamic Price Competition. Quantitative Marketing and Economics 8, 167-205.

Doganoglu, T. and L. Grzybowski (2013). Dynamic Duopoly Competition with Switching Costs and Network Externalities. Review of Network Economics 12(1), 1-25.

Doraszelski, U. and S. Markovich (2007). Advertising Dynamics and Competitive Advantage. RAND Journal of Economics 38, 557-592.

Doraszelski, U. and M. Satterthwaite (2010). Computable Markov-Perfect Industry Dynamics. Rand Journal of Economics 41(2), 215-243. 
Dranove, D. and N. Gandal (2003). The DVD vs. DIVX standard war: Network effects and empirical evidence of preannouncement effects. Journal of Economics $\&$ Management Strategy 12, 363-386.

Dubé, J.-P., G. J. Hitsch, and P. E. Rossi (2009). Do Switching Costs Make Markets Less Competitive? Journal of Marketing Research 46, 435-445.

Dubé, J.-P. H., G. J. Hitsch, and P. K. Chintagunta (2010). Tipping and Concentration in Markets with Indirect Network Effects. Marketing Science 29(2), 216-249.

ECAFSS (2006). Competition Issues In Retail Banking and Payments Systems Markets In The EU. European Competition Authorities Financial Services Subgroup.

ECC (2005). Implementation of Mobile Number Portability In CEPT Countries. Electronic Communications Committee (ECC) within the European Conference of Postal and Telecommunications Administrations (CEPT).

Farrell, J. and P. Klemperer (2007). Coordination and Lock-in: Competition with Switching Costs and Network Effects. In M. Armstrong and R. Porter (Eds.), Handbook of Industrial Organization, Volume 3. Elsevier.

Fudenberg, D. and J. Tirole (1984). The fat-cat effect, the puppy-dog ploy and the lean and hungry look. American Economic Review 74, 361-366.

Gandal, N., M. Kende, and R. Rob (2000). The Dynamics of Technological Adoption in Hardware/Software Systems: The Case of Compact Disc Players. Rand Journal of Economics 31, $43-61$.

Klemperer, P. (1987a). The Competitiveness of Markets with Switching Costs. RAND Journal of Economics 18, 138-150.

Klemperer, P. (1987b). Markets with Consumer Switching Costs. Quarterly Journal of Economics 102, 375-394.

Laffont, J.-J., P. Rey, and J. Tirole (1998). Network Competition: II. Price Discrimination. RAND Journal of Economics 29(1), 38-56.

Llobet, G. and M. Manove (2006). Network Size and Network Capture. Boston University.

Mitchell, M. F. and A. Skrzypacz (2006). Network externalities and long-run market shares. Economic Theory 29, 621-648. 
Pakes, A. and P. McGuire (1994). Computing Markov-Perfect Nash Equilibria: Numerical Implications of a Dynamic Differentiated Product Model. Rand Journal of Economics 25(4), 555-589.

Pakes, A. and P. McGuire (2001). Stochastic Algorithms, Symmetric Markov Perfect Equilibrium, and the 'Curse' of Dimensionality. Econometrica 69(5), 1261-1281.

Park, M. (2011). The Economic Impact of Wireless Number Portability. Journal of Industrial Economics 59, 714-745.

Shi, M., J. Chiang, and B.-D. Rhee (2006). Price Competition with Reduced Consumer Switching Costs: The Case of "Wireless Number Portability" in the Cellular Phone Industry. Management Science 52, 27-38.

Shum, M. (2004). Does Advertising Overcome Brand Loyalty? Evidence from the Breakfast-Cereals Market. Journal of Economics 83 Management Strategy 13(2), 241-272.

Shy, O. (2001). The Economics of Network Industries. Cambridge University Press.

Suleymanova, I. and C. Wey (2011). Bertrand Competition in Markets with Network Effects and Switching Costs. The B.E. Journal of Economic Analysis 8 Policy 11(1), Article 56.

Taylor, C. (2003). Supplier surfing: Competition and consumer behavior in subscription markets. RAND Journal of Economics 34, 223-246.

Train, K. E. (2003). Discrete Choice Methods with Simulation. Cambridge University Press.

Vasconcelos, H. (2005). Tacit Collusion, Cost Asymmetries, and Mergers. RAND Journal of Economics 36, 39-62.

Viard, V. B. (2007). Do switching costs make markets more or less competitive? The case of 800-number portability. Rand Journal of Economics 38, 146-163. 
(1) Firm 1's policy function

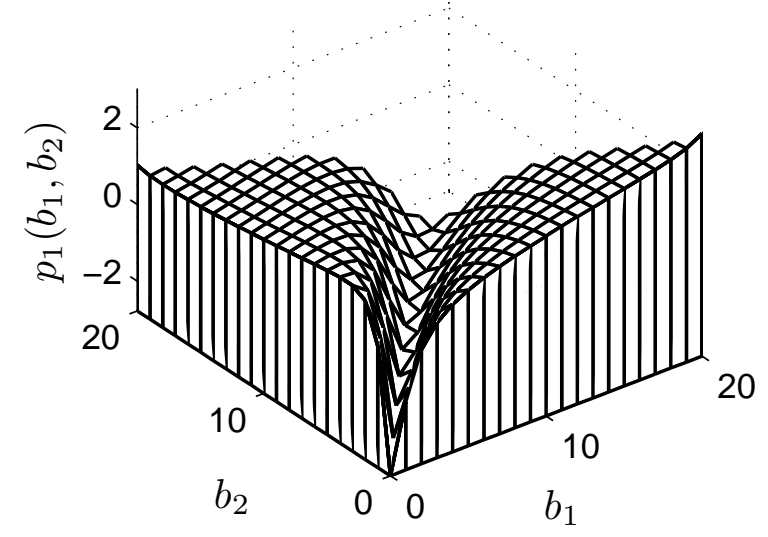

(3) Transient distribution after 15 periods

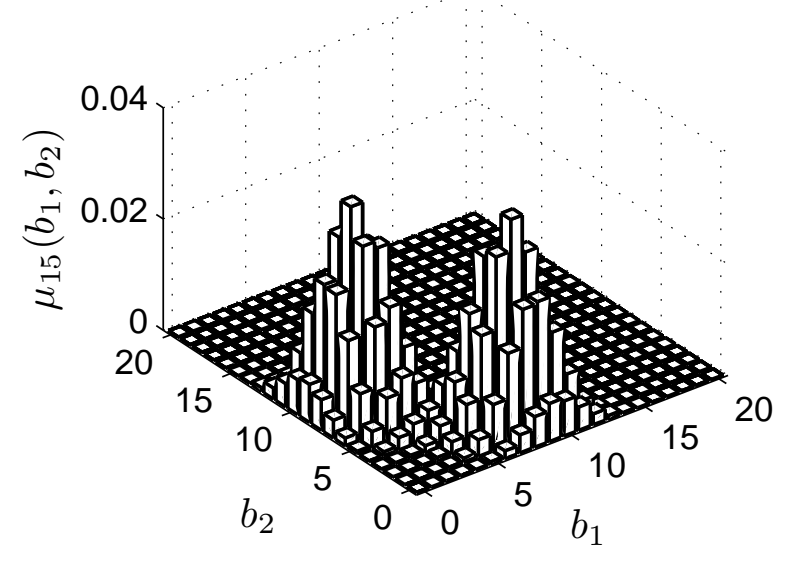

(5) Probability that firm 1 makes a sale

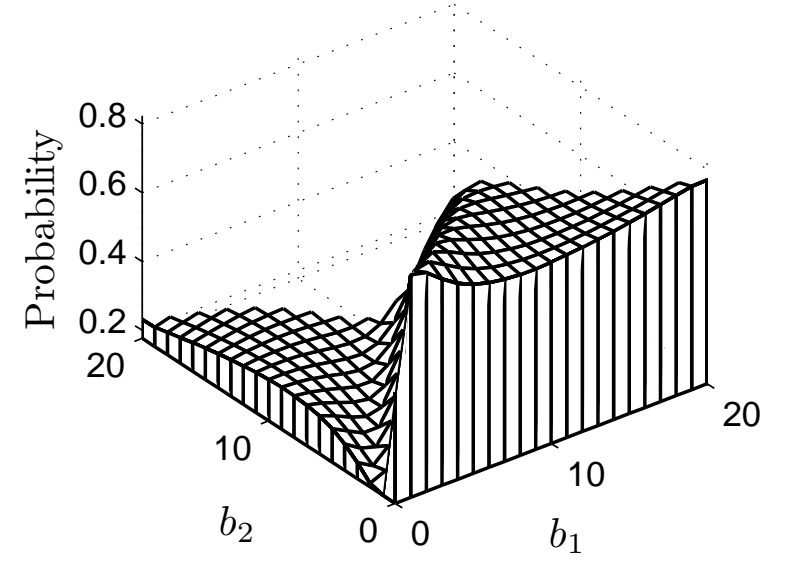

(2) Firm 1's value function

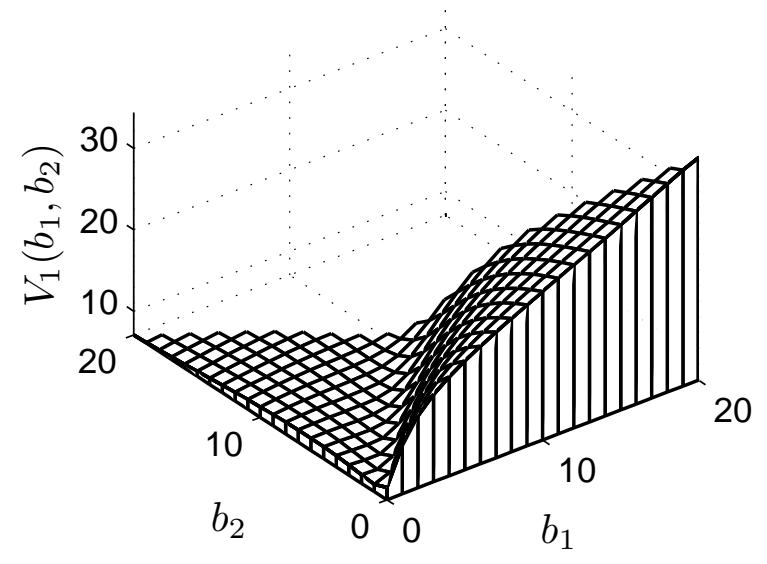

(4) Limiting distribution

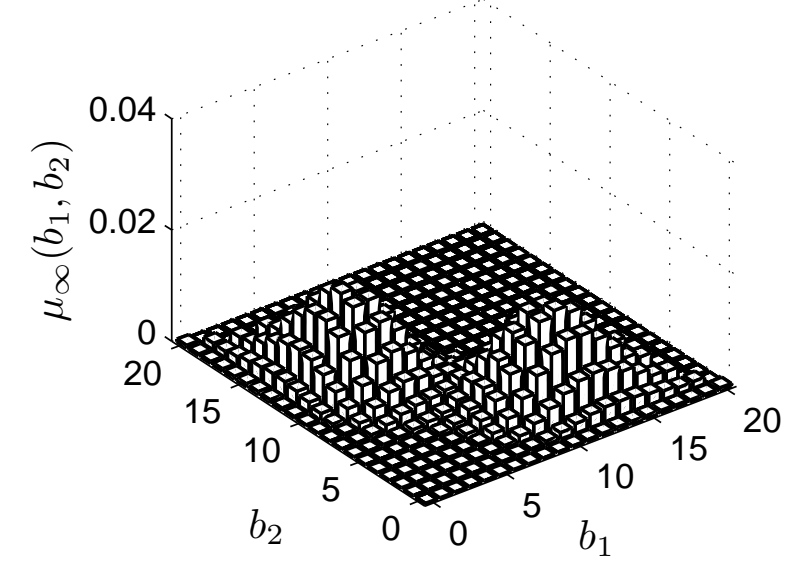

(6) Resultant forces

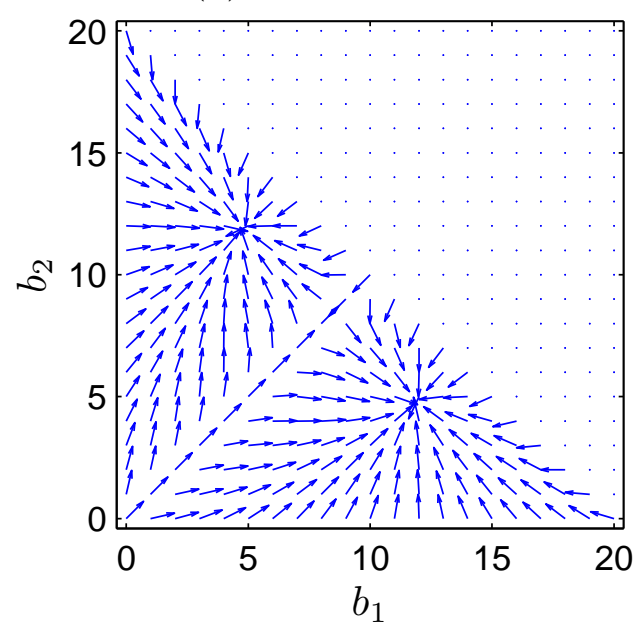

Figure 1. Tipping equilibrium: $v_{0}=-\infty, \delta=0.06, \theta=2.2, k=1$ 
(1) Firm 1's policy function

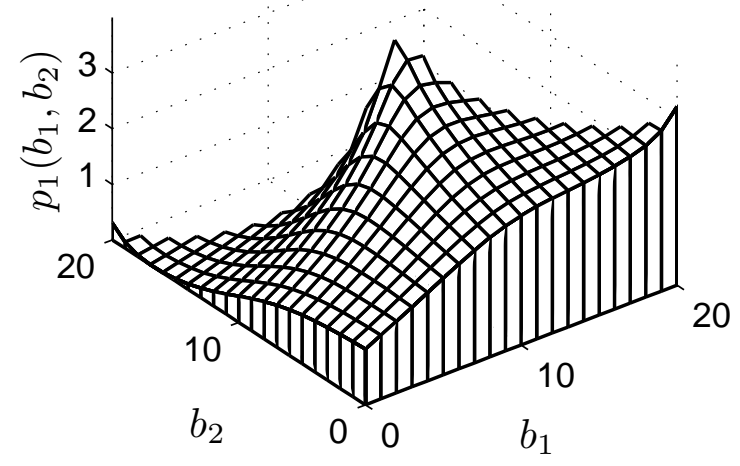

(3) Transient distribution after 15 periods

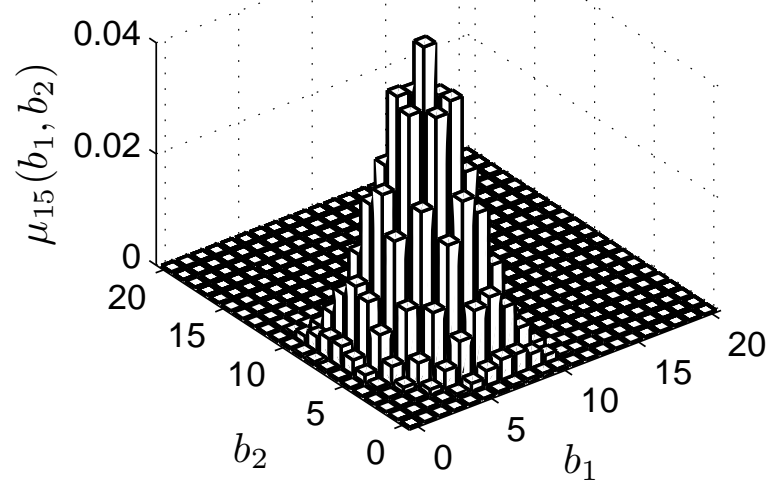

(5) Probability that firm 1 makes a sale

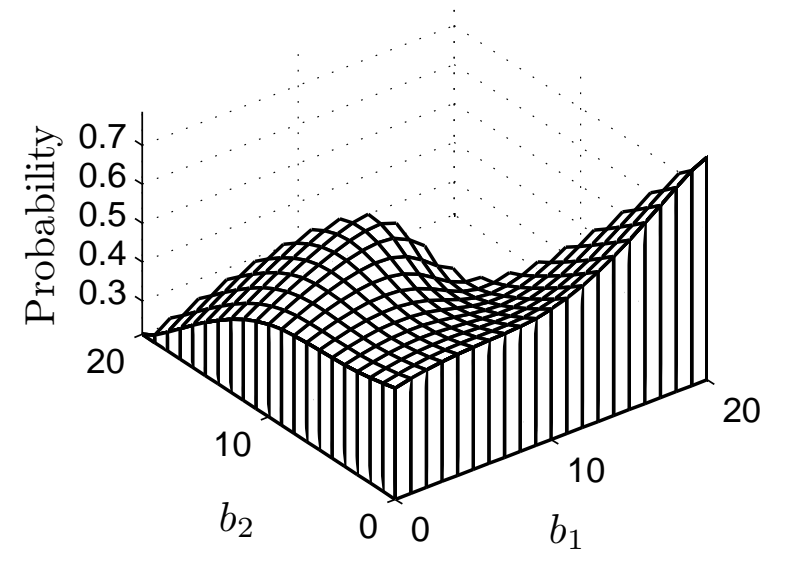

(2) Firm 1's value function

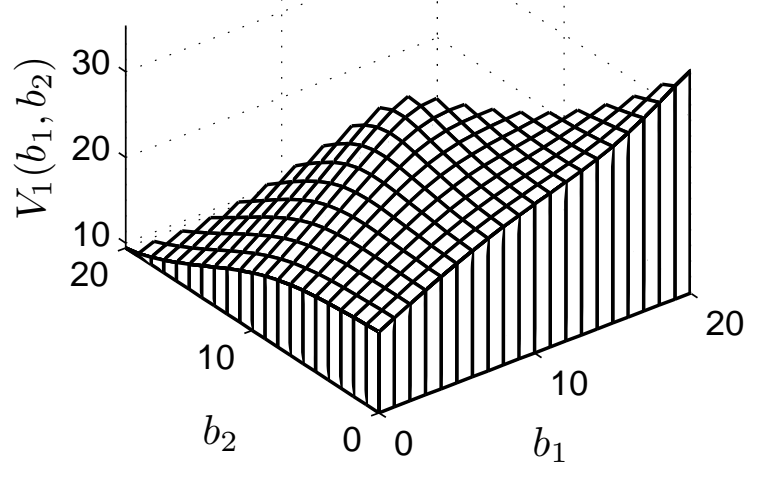

(4) Limiting distribution

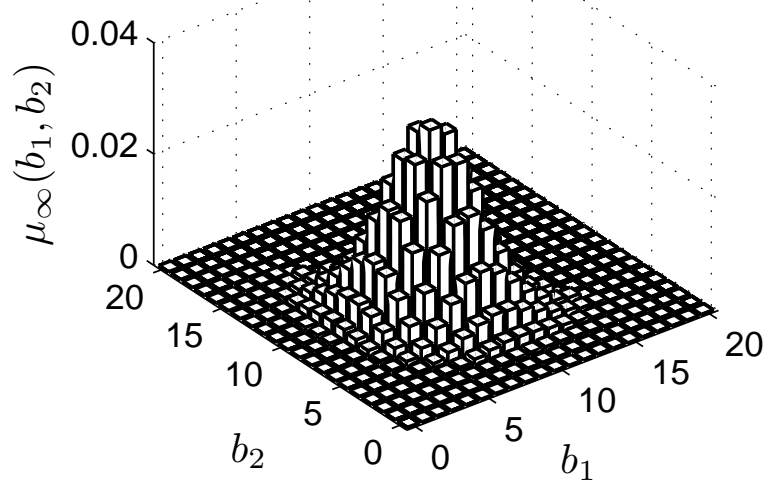

(6) Resultant forces

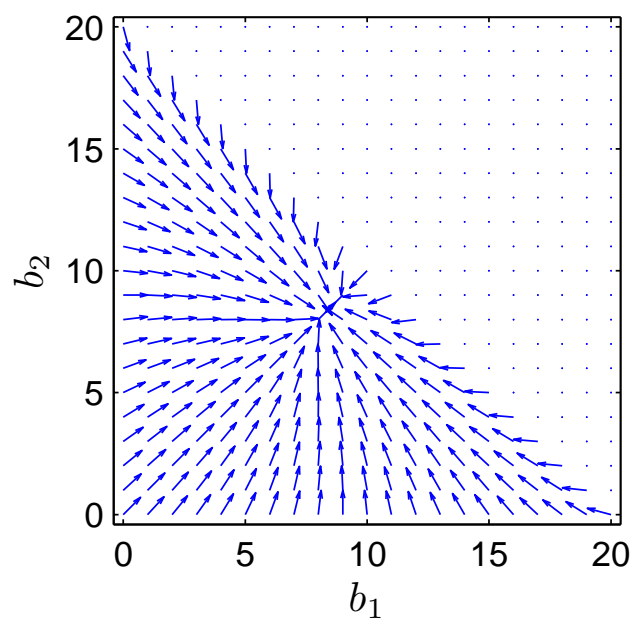

Figure 2. Peaked equilibrium: $v_{0}=-\infty, \delta=0.06, \theta=2.2, k=2$ 
(1) Installed base

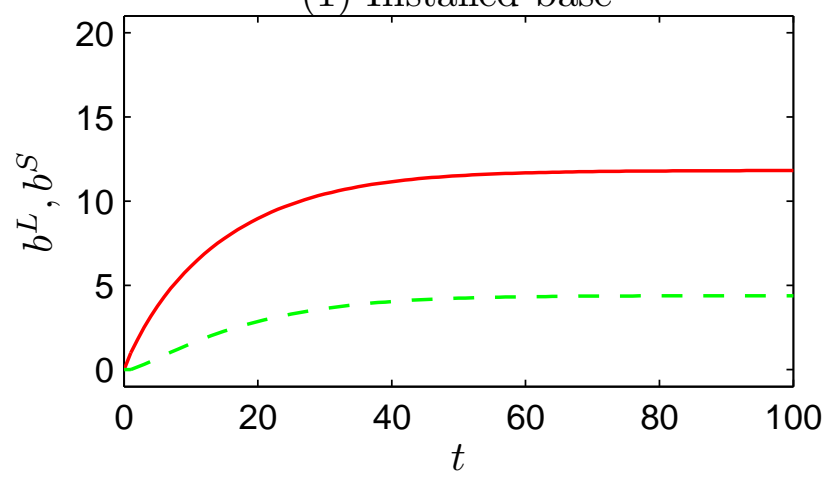

(3) Price

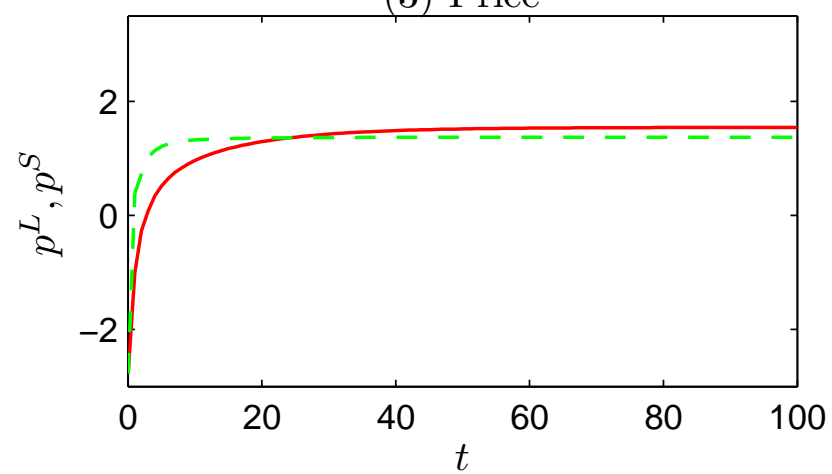

(5) Probability of sale

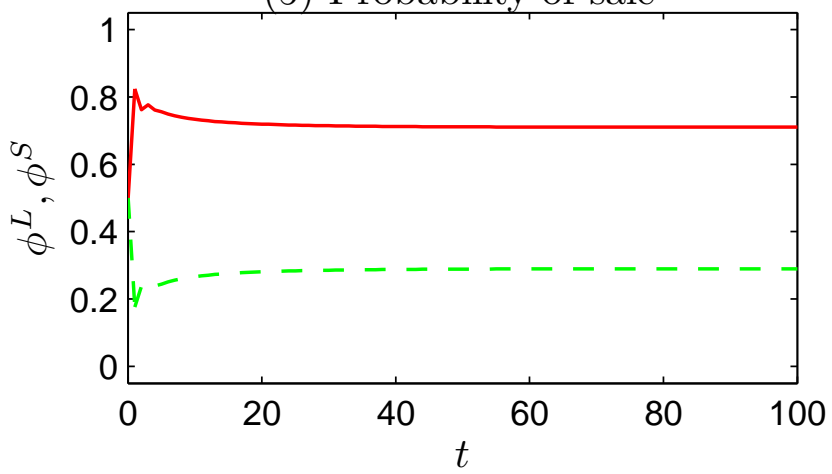

(7) Profit

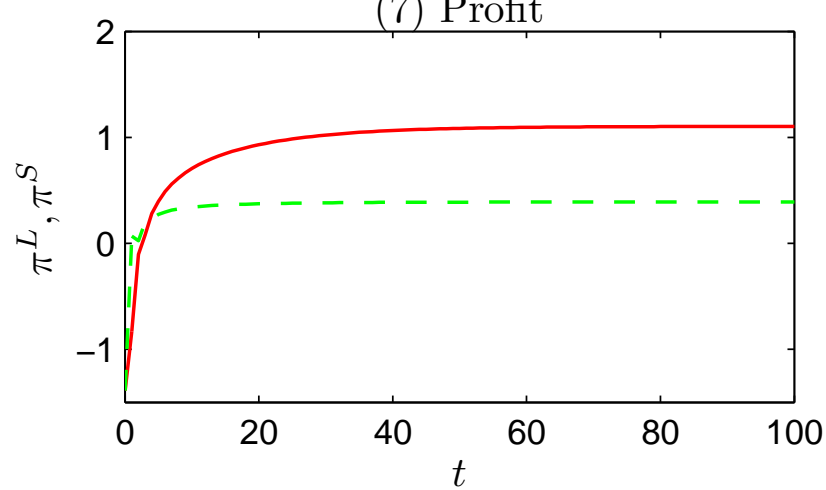

(2) Installed base

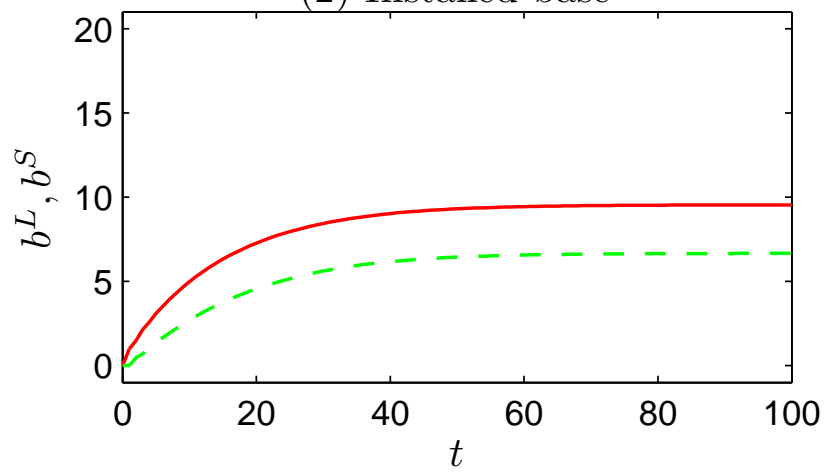

(4) Price

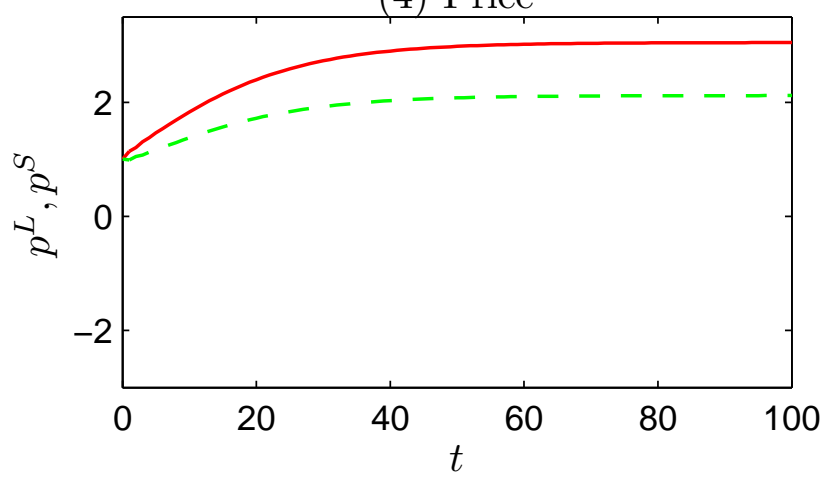

(6) Probability of sale

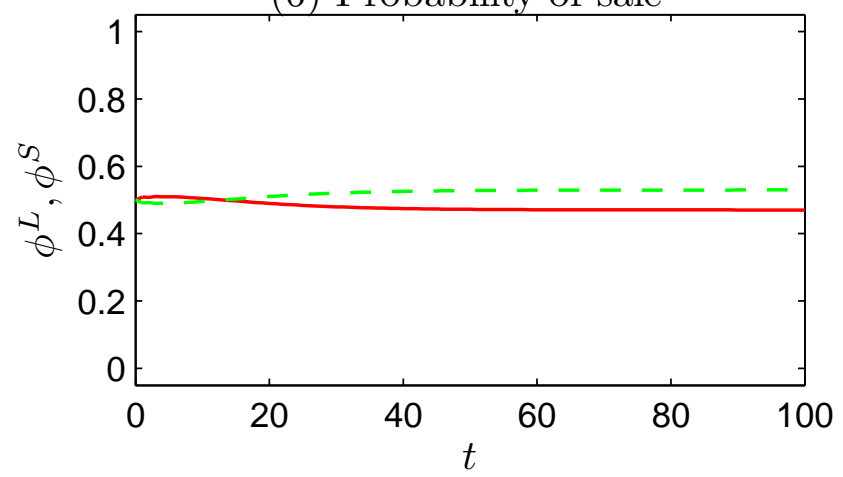

(8) Profit

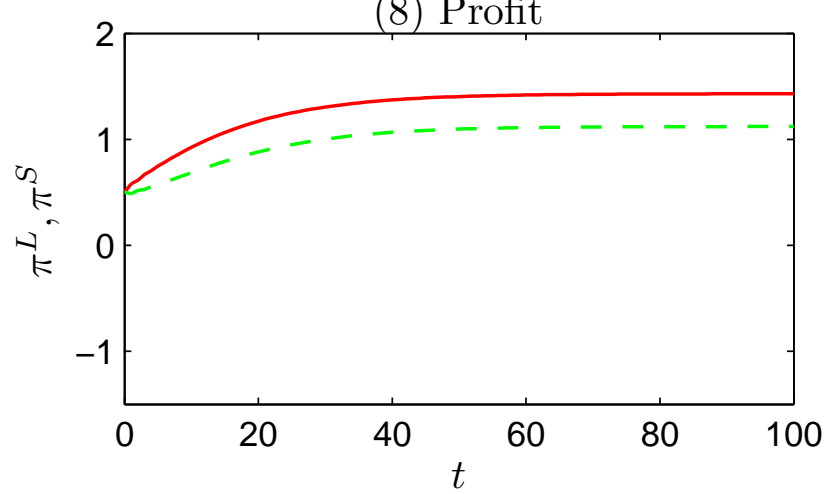

Figure 3. Time paths. Left column: Tipping equilibrim. Right column: Peaked equilibrium. Solid line: the larger firm. Dashed line: the smaller firm. 
(1) $v_{0}=-\infty, \delta=0.05$

(2) $v_{0}=-\infty, \delta=0.06$

(3) $v_{0}=-\infty, \delta=0.07$
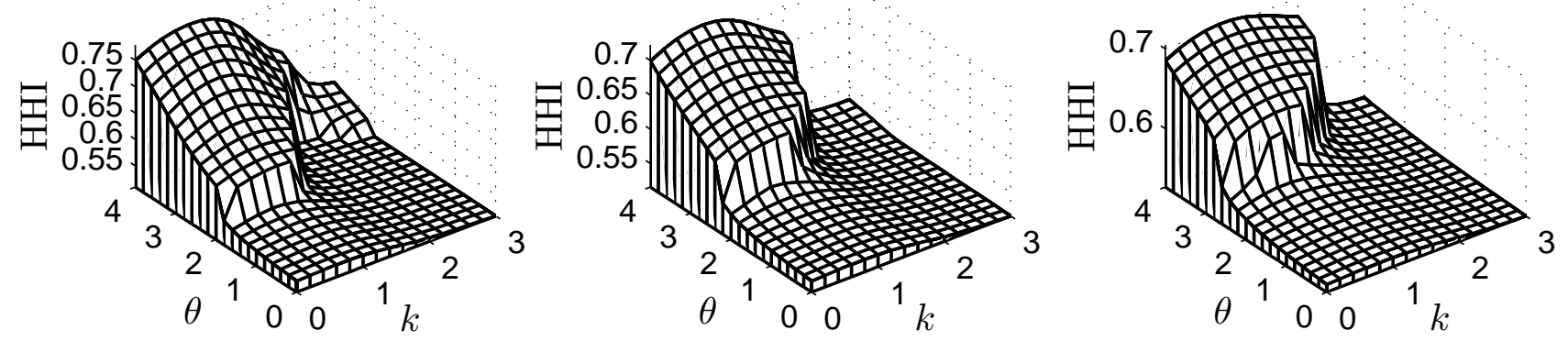

(4) $v_{0}=0, \delta=0.05$

(5) $v_{0}=0, \delta=0.06$

(6) $v_{0}=0, \delta=0.07$
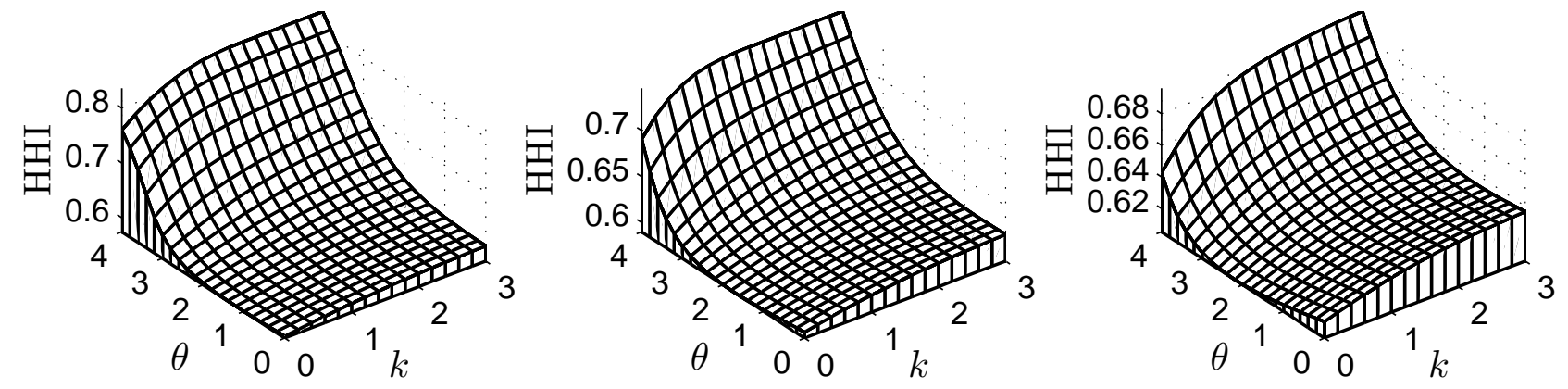

Figure 4. Expected HHI 
(1) $v_{0}=-\infty, \theta=0$

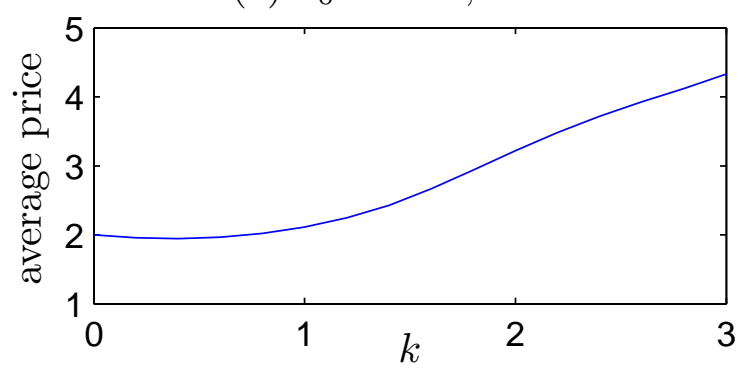

(3) $v_{0}=-\infty, \theta=1$

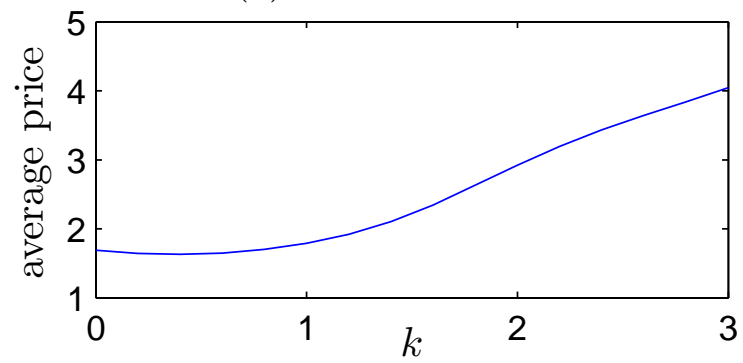

(5) $v_{0}=-\infty, \theta=2$

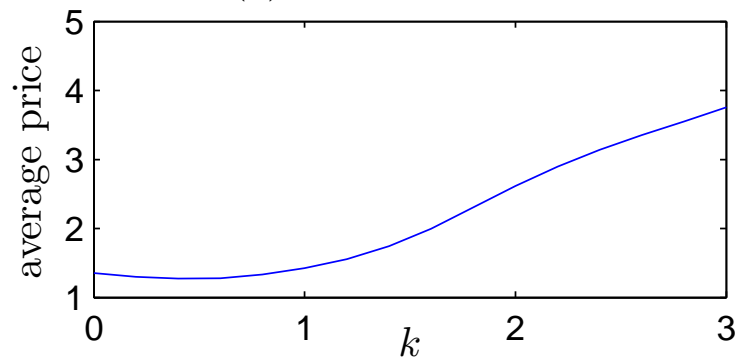

(7) $v_{0}=-\infty, \theta=3$

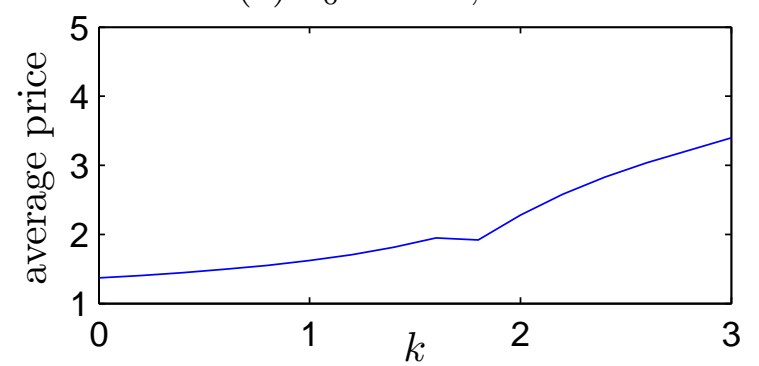

(9) $v_{0}=-\infty, \theta=4$

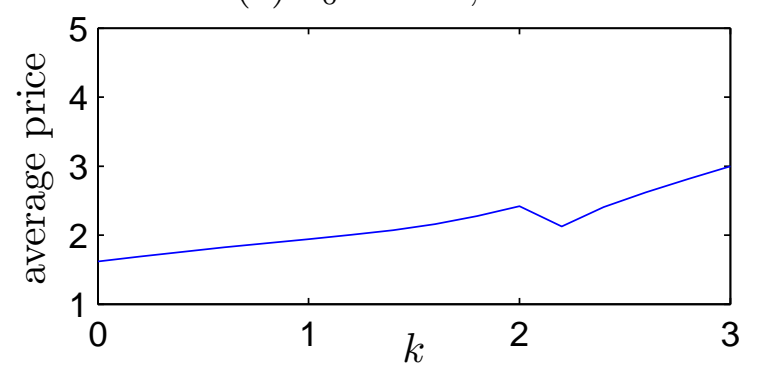

(2) $v_{0}=0, \theta=0$

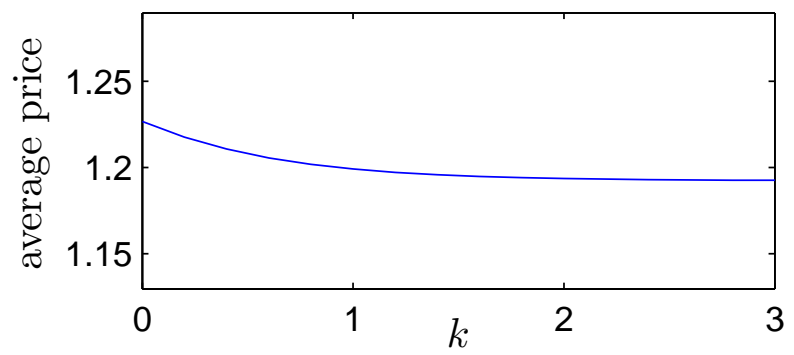

(4) $v_{0}=0, \theta=1$

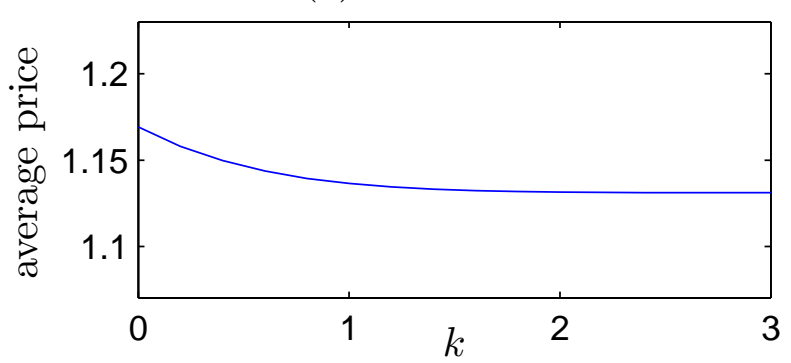

(6) $v_{0}=0, \theta=2$

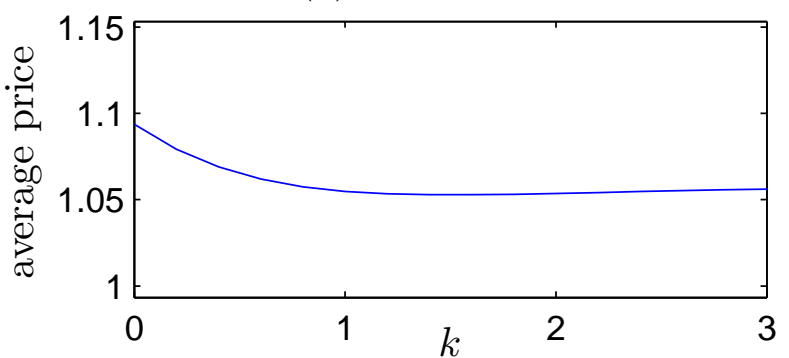

(8) $v_{0}=0, \theta=3$

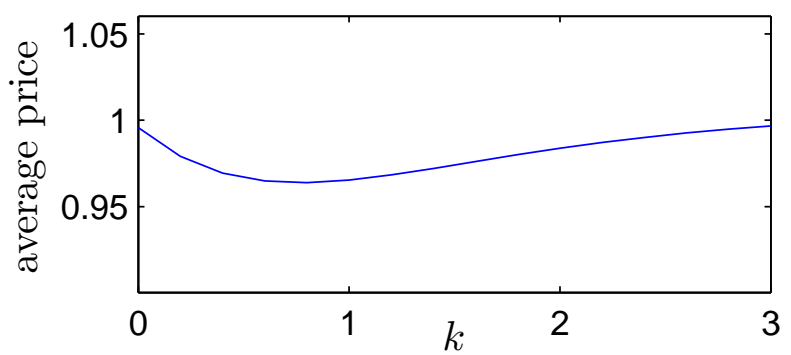

(10) $v_{0}=0, \theta=4$

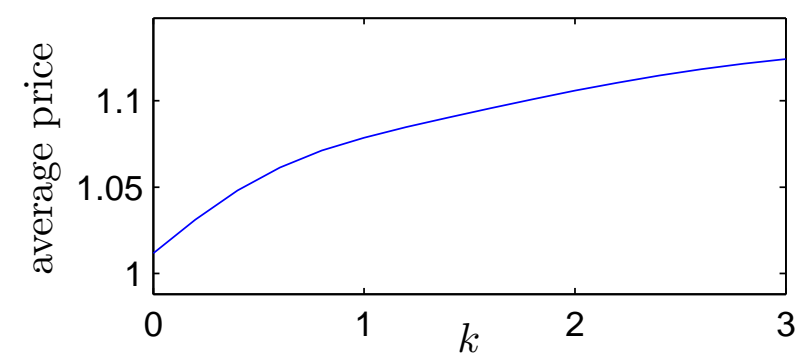

Figure 5. Average price: $\delta=0.06$ 
(1) $\theta=1$

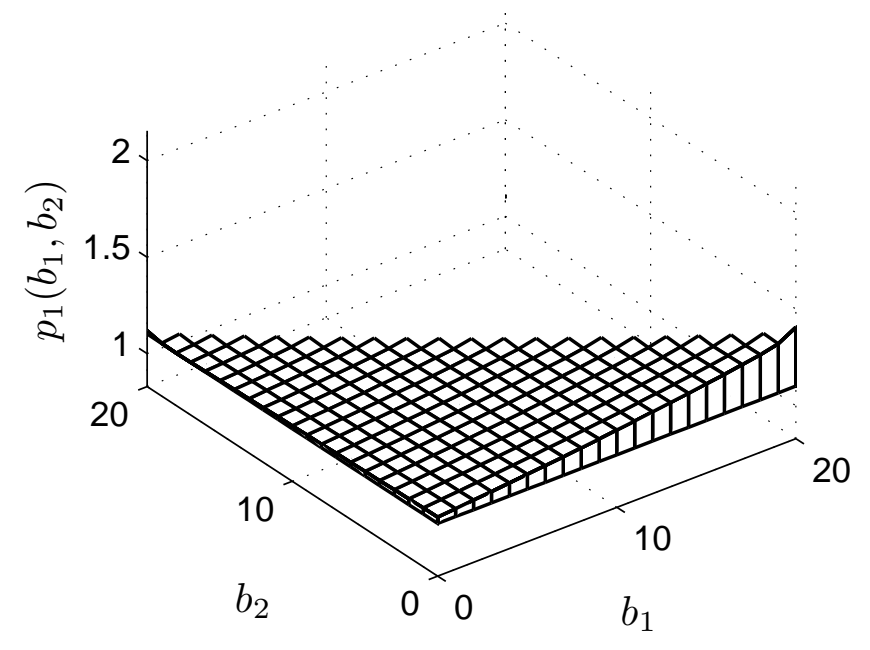

(2) $\theta=3$

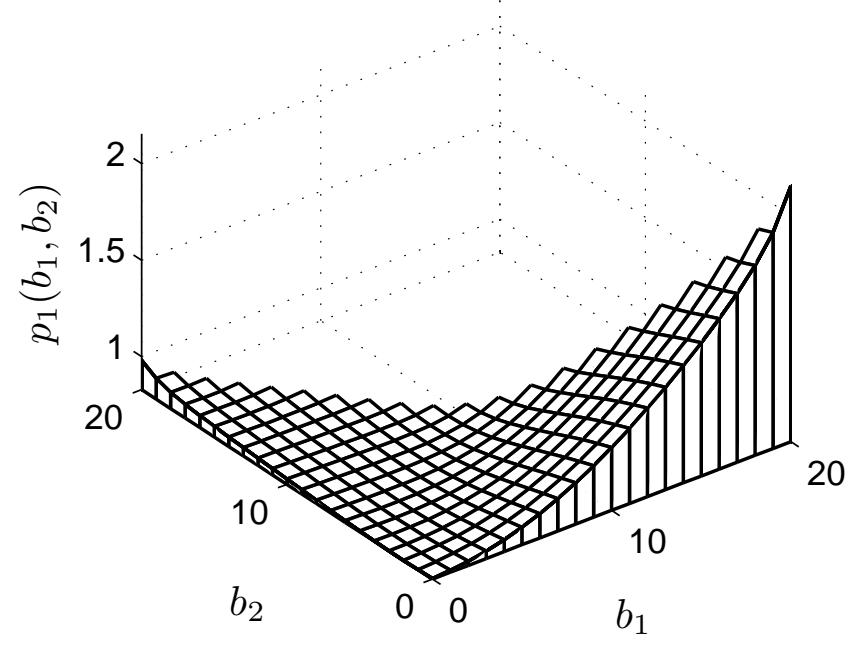

Figure 6. Firm 1's policy function: $v_{0}=0, \delta=0.05, k=0$ 
Table 1 . The effects of switching costs in network industries: a summary

(1) Market concentration

\begin{tabular}{lll}
\hline & Without viable outside option & With viable outside option \\
\hline \multirow{2}{*}{ Modest network effects } & $\begin{array}{l}\text { Market concentration decreases in switching } \\
\text { costs. }\end{array}$ & $\begin{array}{l}\text { Market concentration increases in } \\
\text { switching costs. }\end{array}$ \\
\hline \multirow{2}{*}{ Strong network effects } & $\begin{array}{l}\text { Market concentration first increases then } \\
\text { decreases in switching costs. }\end{array}$ & $\begin{array}{l}\text { Market concentration increases in } \\
\text { switching costs. }\end{array}$ \\
\hline
\end{tabular}

(2) Prices

\begin{tabular}{lll}
\hline & Without viable outside option & With viable outside option \\
\hline Modest network effects & $\begin{array}{l}\text { Prices first slightly decrease then increase in } \\
\text { switching costs. }\end{array}$ & Prices decrease in switching costs. \\
\hline Strong network effects & Prices increase in switching costs. & Prices increase in switching costs. \\
\hline
\end{tabular}




\section{Appendices}

\section{Deriving the First-order Condition}

Let $\psi_{i}(b, p)$ denote the objective function in the maximization problem in Firm $i$ 's Bellman equation, Eq. (4):

$$
\psi_{i}(b, p) \equiv E_{r}\left[\phi_{r i}\left(b, p_{i}, p_{-i}(b)\right) p_{i}+\beta \sum_{j=0}^{2} \phi_{r j}\left(b, p_{i}, p_{-i}(b)\right) \bar{V}_{i j}(b)\right] .
$$

Below we derive the first-order condition. First,

$$
\frac{\partial \psi_{i}(b, p)}{\partial p_{i}}=0 \Leftrightarrow E_{r}\left[\frac{\partial \phi_{r i}}{\partial p_{i}} p_{i}+\phi_{r i}+\beta \sum_{j=0}^{2} \frac{\partial \phi_{r j}}{\partial p_{i}} \bar{V}_{i j}\right]=0 .
$$

Using the properties of logit demand (see Train (2003, Page 62)),

$$
\begin{aligned}
\frac{\partial \phi_{r i}}{\partial p_{i}} & =\frac{\partial \bar{u}_{r i}}{\partial p_{i}} \phi_{r i}\left(1-\phi_{r i}\right)=-\phi_{r i}\left(1-\phi_{r i}\right), \text { and } \\
\frac{\partial \phi_{r j}}{\partial p_{i}} & =-\frac{\partial \bar{u}_{r i}}{\partial p_{i}} \phi_{r i} \phi_{r j}=\phi_{r i} \phi_{r j}, \text { for } j \neq i,
\end{aligned}
$$

where $\bar{u}_{r i}$ is the utility that a consumer loyal to good $r$ gets from buying good $i$, excluding $\epsilon_{i}$ :

$$
\bar{u}_{r i}=v_{i}+\mathbf{1}(i \neq 0) \theta g\left(b_{i}\right)-p_{i}-\mathbf{1}(r \neq 0, i \neq 0, i \neq r) k .
$$

Therefore,

$$
\begin{aligned}
\frac{\partial \psi_{i}\left(p_{i} ; b\right)}{\partial p_{i}}=0 & \Leftrightarrow E_{r}\left[-\phi_{r i}\left(1-\phi_{r i}\right) p_{i}+\phi_{r i}+\beta\left[-\phi_{r i}\left(1-\phi_{r i}\right)\right] \bar{V}_{i i}+\beta \sum_{j \neq i} \phi_{r i} \phi_{r j} \bar{V}_{i j}\right]=0 \\
& \Leftrightarrow E_{r}\left[-\phi_{r i}\left(1-\phi_{r i}\right)\left(p_{i}+\beta \bar{V}_{i i}\right)+\phi_{r i}+\beta \phi_{r i} \sum_{j \neq i} \phi_{r j} \bar{V}_{i j}\right]=0 .
\end{aligned}
$$

\section{Switching Costs and Prices: Detailed Results}

Table A1 reports on the effects of switching costs on the average price for a broad set of parameterizations. They confirm the findings reported in Subsection 4.2 in the paper.

The table reports statistics for the percentage change in the equilibrium average price when the switching cost increases from $k$ to $k+0.2$, for $v_{0} \in\{-\infty,-2,0\}, \delta \in\{0.04,0.05, \ldots, 0.1\}, \theta \in$ $\{0,0.2, \ldots, 4\}$, and $k \in\{0,0.2, \ldots, 2.8\}$. In the table, the parameterizations are first grouped according to the value of $v_{0}$, and then within each $v_{0}$ group, they are further divided into subgroups according to the value of $\theta$. The statistics reported are the 5 th, $25 \mathrm{th}, 50 \mathrm{th}, 75 \mathrm{th}$, and 95 th percentiles, as well as the percentage of price changes that are negative.

The first three rows in the table show that the quality of the outside option plays an important role in determining the effects of switching costs on price. An increase in the switching cost tends to increase price if there does not exist a viable outside option, but this is gradually reversed as the quality of the outside option increases. When $v_{0}=-\infty$, an increase in the switching cost reduces 
price only $10.1 \%$ of the time (that is, for $10.1 \%$ of the parameterizations considered). That number increases to $20.7 \%$ for $v_{0}=-2$, and further jumps to $62 \%$ for $v_{0}=0$.

The remaining rows in the table show that a stronger network effect makes it more likely that the average price will increase in the switching cost. This pattern is particularly salient when there exists a viable outside option. For example, with $v_{0}=-2$, the percentage of negative price changes is $33.3 \%$ when $\theta \in[0,1)$, but drops to $12.4 \%$ when $\theta \in[3,4]$. With $v_{0}=0$, the percentage of negative price changes is $93.7 \%$ when $\theta \in[0,1)$, but drops dramatically to $27.0 \%$ when $\theta \in[3,4]$.

\section{Switching Costs and Welfare: Detailed Results}

Here we examine the effects of switching costs on expected producer surplus, consumer surplus, and total welfare (the sum of the previous two measures), based on the limiting distribution. ${ }^{1}$ We consider the changes in the equilibrium levels of these measures when the switching cost increases from $k$ to $k+0.2$, for $v_{0} \in\{-\infty,-2,0\}, \delta \in\{0.04,0.05, \ldots, 0.1\}, \theta \in\{0,0.2, \ldots, 4\}$, and $k \in$ $\{0,0.2, \ldots, 2.8\}$.

Table A2 reports statistics for the percentage change in producer surplus. It shows that switching costs help the firms when there does not exist a viable outside option, but become more and more harmful to the firms as $v_{0}$ increases. Producer surplus increases in the switching cost $89.9 \%$ of the time when $v_{0}=-\infty$, but decreases in the switching cost $92.5 \%$ of the time when $v_{0}=0$. For a same $v_{0}$, a stronger network effect makes it more likely that the firms will benefit from the switching cost. For example, with $v_{0}=-2$, the firms suffer a loss due to an increase in the switching cost $86.1 \%$ of the time if $\theta \in[0,1)$, but only $14.0 \%$ of the time if $\theta \in[3,4]$.

The existence of a viable outside option gives consumers greater flexibility in their product choices and restrains firms' ability to raise prices. Therefore a stronger outside option makes switching costs more harmful (less beneficial) to firms and less harmful to consumers. On the other hand, when the network effect is strong, switching costs are less capable of reducing the size of the market and more likely to result in price increases (see the discussion in the paper on the effects of switching costs on prices), and therefore firms are more likely to benefit from switching costs.

Prior studies on switching costs, which often assume a fixed market size and do not consider network effects, generally find that switching costs raise oligopoly profits (see Farrell and Klemperer (2007, Section 2.4.4.) and the references cited therein). By incorporating network effects and allowing the market size to be endogenously determined, this model allows us to look at a broader picture, in which the relationship between switching costs and firm profits depends on the strength of network effects and the quality of the outside option.

Turning to consumer surplus (Table A3) and total welfare (Table A4), we find that both of them consistently decrease in the switching cost. ${ }^{2}$ The results show that consumers are harmed by switching costs. And even when firms benefit from switching costs, consumers' losses more than offset firms' gains and result in a reduction in total welfare. In the case with a viable outside option, both firms and consumers will benefit from a reduction in switching costs. However, if there does not exist a viable outside option, then consumer advocates and industry lobbyists are likely to be on opposing sides of a policy debate, with the former in favor of reducing switching costs and the latter against it.

\footnotetext{
${ }^{1}$ The producer surplus is equal to the combined profits of the firms, and the consumer surplus is the log-sum term (Train (2003, Pages 59-60)). In the case without a viable outside option, the producer surplus is equal to the average price, since the sum of the firms' expected sales is always 1 and the marginal cost is normalized to 0 .

${ }^{2}$ Note that Tables A3 and A4 report on the actual changes in consumer surplus and total welfare rather than the percentage changes, as the latter are not invariant to normalization of the intrinsic qualities of the goods.
} 


\section{Extension: Paying Consumers to Switch}

In this Appendix, I consider a scenario in which firms subsidize switchers by paying them a fixed portion of the switching cost, to assess the impact of such differential pricing on the results in my model.

With this modification, the utility that a consumer loyal to good $r$ gets from buying good $i$ is

$$
u_{r i}=v_{i}+\mathbf{1}(i \neq 0) \theta g\left(b_{i}\right)-p_{i}-\mathbf{1}(r \neq 0, i \neq 0, i \neq r)(1-d) k+\epsilon_{i}
$$

where $d \in[0,1]$ denotes the percentage of the switching cost that is subsidized by the firm. The model in the main text corresponds to the case with $d=0$.

Firm $i$ 's Bellman equation becomes

$$
V_{i}(b)=\max _{p_{i}} E_{r}\left[\phi_{r i}\left(b, p_{i}, p_{-i}(b)\right)\left(p_{i}-\mathbf{1}(r \neq 0, r \neq i) d k\right)+\beta \sum_{j=0}^{2} \phi_{r j}\left(b, p_{i}, p_{-i}(b)\right) \bar{V}_{i j}(b)\right],
$$

where the term $-\mathbf{1}(r \neq 0, i \neq r) d k$ indicates that firm $i$ pays a subsidy in the amount of $d k$ to consumer $r$ if she is a switcher.

Following the derivation steps in Appendix 1, we obtain the first-order condition:

$$
E_{r}\left[-\phi_{r i}\left(1-\phi_{r i}\right)\left(p_{i}-\mathbf{1}(r \neq 0, r \neq i) d k+\beta \bar{V}_{i i}\right)+\phi_{r i}+\beta \phi_{r i} \sum_{j \neq i} \phi_{r j} \bar{V}_{i j}\right]=0 .
$$

The switching cost subsidy partially offsets the switching costs, and therefore its main impact is to reduce the effectiveness of switching costs in changing industry dynamics and the market outcome. The results from the model are consistent with this intuition.

Figure A1 presents the results for $v_{0}=-\infty, \delta=0.06$, and $d=0.5$ (i.e., the switching cost is split evenly between the firm and the switcher). First, we see that when switching cost subsidy is incorporated into the model, switching costs continue to have the ability to transform the market equilibrium from Tipping to Peaked. The first three rows of Figure A1 show Firm 1's policy function, the resultant forces, and the price time paths, respectively, for $\theta=2.2$. As we increase the switching cost $k$ from 2 to 5 , the market equilibrium changes from Tipping (left column) to Peaked (right column). The sharp contrast between these two types of market outcome, as discussed in the main text, continues to exist, including the difference in the firms' policy function (Panel 1 vs. Panel 2), the evolution of the industry towards asymmetric states with high market concentration (Panel 3) vs. symmetric states with low market concentration (Panel 4), and fierce price competition (Panel 5) vs. high prices due to lack of price competition (Panel 6).

Furthermore, as a consequence of the switching cost subsidy, it now takes a larger switching cost to transform the market equilibrium from Tipping to Peaked. Panel 7 plots the expected HHI for $\theta \in\{0,0.2, \ldots, 4\}$ and $k \in\{0,0.2, \ldots, 6\}$. Comparing this panel with Panel 2 in Figure 4 (which plots the expected HHI for $\theta \in\{0,0.2, \ldots, 4\}$ and $k \in\{0,0.2, \ldots, 3\}$ in the case without switching cost subsidy) reveals that with the switching cost subsidy, a larger switching cost is needed to induce a change in the type of the market equilibrium. For example, as we increase $k$ while holding $\theta$ fixed at 2.2 (Panel 8), the shift of the market equilibrium from Tipping (high HHI) to Peaked (low HHI) occurs around $k=1.2$ when there is no switching cost subsidy, but when there is switching cost subsidy, the shift occurs later, around $k=3.2$. 
Table A1. Percentage change in average price from $k$ to $k+0.2$

$\delta \in[0.04,0.1], k \in[0,3)$

\begin{tabular}{ccccccc}
\hline & \multicolumn{5}{c}{ Percentiles } & \\
\cline { 2 - 5 } & 5 th & 25 th & 50 th & 75 th & 95 th & $\%$ negative \\
\hline$v_{0}=-\infty, \theta \in[0,4]$ & $-1.93 \%$ & $2.83 \%$ & $4.77 \%$ & $6.98 \%$ & $12.95 \%$ & $10.1 \%$ \\
$v_{0}=-2, \theta \in[0,4]$ & $-1.75 \%$ & $0.18 \%$ & $0.86 \%$ & $2.00 \%$ & $3.43 \%$ & $20.7 \%$ \\
$v_{0}=0, \theta \in[0,4]$ & $-0.92 \%$ & $-0.24 \%$ & $-0.02 \%$ & $0.09 \%$ & $0.95 \%$ & $62.0 \%$ \\
\hline$v_{0}=-\infty, \theta \in[0,1)$ & $-1.94 \%$ & $2.43 \%$ & $4.72 \%$ & $6.73 \%$ & $11.96 \%$ & $13.3 \%$ \\
$v_{0}=-\infty, \theta \in[1,2)$ & $-2.29 \%$ & $2.71 \%$ & $5.24 \%$ & $7.62 \%$ & $14.70 \%$ & $12.8 \%$ \\
$v_{0}=-\infty, \theta \in[2,3)$ & $-1.72 \%$ & $3.19 \%$ & $5.27 \%$ & $7.50 \%$ & $14.71 \%$ & $8.2 \%$ \\
$v_{0}=-\infty, \theta \in[3,4]$ & $-1.15 \%$ & $2.83 \%$ & $4.06 \%$ & $6.13 \%$ & $10.47 \%$ & $6.7 \%$ \\
\hline$v_{0}=-2, \theta \in[0,1)$ & $-1.82 \%$ & $-0.36 \%$ & $0.20 \%$ & $0.46 \%$ & $1.05 \%$ & $33.3 \%$ \\
$v_{0}=-2, \theta \in[1,2)$ & $-2.03 \%$ & $0.04 \%$ & $0.57 \%$ & $1.25 \%$ & $2.93 \%$ & $24.4 \%$ \\
$v_{0}=-2, \theta \in[2,3)$ & $-1.75 \%$ & $0.69 \%$ & $1.43 \%$ & $2.57 \%$ & $3.87 \%$ & $14.5 \%$ \\
$v_{0}=-2, \theta \in[3,4]$ & $-1.47 \%$ & $1.15 \%$ & $1.93 \%$ & $2.63 \%$ & $3.67 \%$ & $12.4 \%$ \\
\hline$v_{0}=0, \theta \in[0,1)$ & $-0.70 \%$ & $-0.27 \%$ & $-0.08 \%$ & $-0.02 \%$ & $0.00 \%$ & $93.7 \%$ \\
$v_{0}=0, \theta \in[1,2)$ & $-0.91 \%$ & $-0.31 \%$ & $-0.06 \%$ & $-0.01 \%$ & $0.10 \%$ & $78.7 \%$ \\
$v_{0}=0, \theta \in[2,3)$ & $-1.07 \%$ & $-0.26 \%$ & $-0.01 \%$ & $0.12 \%$ & $0.92 \%$ & $55.4 \%$ \\
$v_{0}=0, \theta \in[3,4]$ & $-0.99 \%$ & $-0.02 \%$ & $0.18 \%$ & $0.56 \%$ & $2.08 \%$ & $27.0 \%$ \\
\hline
\end{tabular}

Table A2. Percentage change in producer surplus from $k$ to $k+0.2$

$\delta \in[0.04,0.1], k \in[0,3)$

\begin{tabular}{ccccccc}
\hline & \multicolumn{5}{c}{ Percentiles } & \\
\cline { 2 - 5 } & 5 th & 25 th & 50 th & 75 th & 95 th & $\%$ negative \\
\hline$v_{0}=-\infty, \theta \in[0,4]$ & $-1.93 \%$ & $2.83 \%$ & $4.77 \%$ & $6.98 \%$ & $12.95 \%$ & $10.1 \%$ \\
$v_{0}=-2, \theta \in[0,4]$ & $-2.26 \%$ & $-0.36 \%$ & $0.31 \%$ & $1.34 \%$ & $2.59 \%$ & $38.2 \%$ \\
$v_{0}=0, \theta \in[0,4]$ & $-2.09 \%$ & $-1.01 \%$ & $-0.43 \%$ & $-0.18 \%$ & $0.19 \%$ & $92.5 \%$ \\
\hline$v_{0}=-\infty, \theta \in[0,1)$ & $-1.94 \%$ & $2.43 \%$ & $4.72 \%$ & $6.73 \%$ & $11.96 \%$ & $13.3 \%$ \\
$v_{0}=-\infty, \theta \in[1,2)$ & $-2.29 \%$ & $2.71 \%$ & $5.24 \%$ & $7.62 \%$ & $14.70 \%$ & $12.8 \%$ \\
$v_{0}=-\infty, \theta \in[2,3)$ & $-1.72 \%$ & $3.19 \%$ & $5.27 \%$ & $7.50 \%$ & $14.71 \%$ & $8.2 \%$ \\
$v_{0}=-\infty, \theta \in[3,4]$ & $-1.15 \%$ & $2.83 \%$ & $4.06 \%$ & $6.13 \%$ & $10.47 \%$ & $6.7 \%$ \\
\hline$v_{0}=-2, \theta \in[0,1)$ & $-2.52 \%$ & $-1.10 \%$ & $-0.29 \%$ & $-0.06 \%$ & $0.12 \%$ & $86.1 \%$ \\
$v_{0}=-2, \theta \in[1,2)$ & $-2.43 \%$ & $-0.61 \%$ & $0.12 \%$ & $0.47 \%$ & $1.66 \%$ & $39.2 \%$ \\
$v_{0}=-2, \theta \in[2,3)$ & $-2.09 \%$ & $0.31 \%$ & $0.87 \%$ & $1.74 \%$ & $2.78 \%$ & $18.5 \%$ \\
$v_{0}=-2, \theta \in[3,4]$ & $-1.60 \%$ & $0.73 \%$ & $1.37 \%$ & $2.03 \%$ & $3.04 \%$ & $14.0 \%$ \\
\hline$v_{0}=0, \theta \in[0,1)$ & $-2.07 \%$ & $-1.07 \%$ & $-0.54 \%$ & $-0.26 \%$ & $-0.13 \%$ & $100.0 \%$ \\
$v_{0}=0, \theta \in[1,2)$ & $-2.45 \%$ & $-1.21 \%$ & $-0.59 \%$ & $-0.28 \%$ & $-0.15 \%$ & $100.0 \%$ \\
$v_{0}=0, \theta \in[2,3)$ & $-2.29 \%$ & $-1.11 \%$ & $-0.48 \%$ & $-0.20 \%$ & $0.10 \%$ & $93.5 \%$ \\
$v_{0}=0, \theta \in[3,4]$ & $-1.72 \%$ & $-0.62 \%$ & $-0.18 \%$ & $-0.04 \%$ & $0.99 \%$ & $79.2 \%$ \\
\hline
\end{tabular}


Table A3. Change in consumer surplus from $k$ to $k+0.2$

$\delta \in[0.04,0.1], k \in[0,3)$

\begin{tabular}{lcccccc}
\hline & \multicolumn{5}{c}{ Percentiles } & \\
\cline { 2 - 5 } & 5 th & 25 th & 50 th & 75 th & 95 th & \% negative \\
\hline$v_{0}=-\infty, \theta \in[0,4]$ & -0.378 & -0.222 & -0.123 & -0.082 & -0.026 & $99.0 \%$ \\
$v_{0}=-2, \theta \in[0,4]$ & -0.076 & -0.047 & -0.027 & -0.016 & -0.007 & $99.9 \%$ \\
$v_{0}=0, \theta \in[0,4]$ & -0.024 & -0.009 & -0.005 & -0.002 & -0.001 & $100.0 \%$ \\
\hline$v_{0}=-\infty, \theta \in[0,1)$ & -0.388 & -0.246 & -0.129 & -0.081 & -0.031 & $100.0 \%$ \\
$v_{0}=-\infty, \theta \in[1,2)$ & -0.412 & -0.249 & -0.129 & -0.081 & -0.025 & $100.0 \%$ \\
$v_{0}=-\infty, \theta \in[2,3)$ & -0.425 & -0.235 & -0.124 & -0.086 & -0.022 & $99.2 \%$ \\
$v_{0}=-\infty, \theta \in[3,4]$ & -0.288 & -0.170 & -0.114 & -0.080 & -0.029 & $97.3 \%$ \\
\hline$v_{0}=-2, \theta \in[0,1)$ & -0.036 & -0.022 & -0.014 & -0.010 & -0.005 & $100.0 \%$ \\
$v_{0}=-2, \theta \in[1,2)$ & -0.060 & -0.034 & -0.021 & -0.014 & -0.008 & $100.0 \%$ \\
$v_{0}=-2, \theta \in[2,3)$ & -0.079 & -0.057 & -0.033 & -0.021 & -0.011 & $100.0 \%$ \\
$v_{0}=-2, \theta \in[3,4]$ & -0.084 & -0.063 & -0.047 & -0.033 & -0.016 & $99.7 \%$ \\
\hline$v_{0}=0, \theta \in[0,1)$ & -0.009 & -0.004 & -0.002 & -0.001 & -0.001 & $100.0 \%$ \\
$v_{0}=0, \theta \in[1,2)$ & -0.014 & -0.006 & -0.003 & -0.002 & -0.001 & $100.0 \%$ \\
$v_{0}=0, \theta \in[2,3)$ & -0.025 & -0.010 & -0.005 & -0.003 & -0.001 & $100.0 \%$ \\
$v_{0}=0, \theta \in[3,4]$ & -0.035 & -0.016 & -0.009 & -0.005 & -0.002 & $100.0 \%$ \\
\hline
\end{tabular}

Table A4. Change in total welfare from $k$ to $k+0.2$

$\delta \in[0.04,0.1], k \in[0,3)$

\begin{tabular}{lcccccc}
\hline & \multicolumn{5}{c}{ Percentiles } & \\
\cline { 2 - 5 } & 5 th & 25 th & 50 th & 75 th & 95 th & \% negative \\
\hline$v_{0}=-\infty, \theta \in[0,4]$ & -0.089 & -0.054 & -0.038 & -0.024 & -0.010 & $99.8 \%$ \\
$v_{0}=-2, \theta \in[0,4]$ & -0.056 & -0.037 & -0.027 & -0.015 & -0.007 & $100.0 \%$ \\
$v_{0}=0, \theta \in[0,4]$ & -0.029 & -0.014 & -0.008 & -0.004 & -0.002 & $100.0 \%$ \\
\hline$v_{0}=-\infty, \theta \in[0,1)$ & -0.077 & -0.055 & -0.040 & -0.023 & -0.010 & $100.0 \%$ \\
$v_{0}=-\infty, \theta \in[1,2)$ & -0.075 & -0.057 & -0.041 & -0.023 & -0.009 & $100.0 \%$ \\
$v_{0}=-\infty, \theta \in[2,3)$ & -0.092 & -0.053 & -0.040 & -0.025 & -0.009 & $99.8 \%$ \\
$v_{0}=-\infty, \theta \in[3,4]$ & -0.107 & -0.048 & -0.032 & -0.024 & -0.011 & $99.5 \%$ \\
\hline$v_{0}=-2, \theta \in[0,1)$ & -0.058 & -0.033 & -0.020 & -0.011 & -0.006 & $100.0 \%$ \\
$v_{0}=-2, \theta \in[1,2)$ & -0.060 & -0.038 & -0.024 & -0.013 & -0.007 & $100.0 \%$ \\
$v_{0}=-2, \theta \in[2,3)$ & -0.054 & -0.041 & -0.028 & -0.015 & -0.008 & $100.0 \%$ \\
$v_{0}=-2, \theta \in[3,4]$ & -0.051 & -0.036 & -0.030 & -0.023 & -0.011 & $100.0 \%$ \\
\hline$v_{0}=0, \theta \in[0,1)$ & -0.018 & -0.009 & -0.005 & -0.002 & -0.001 & $100.0 \%$ \\
$v_{0}=0, \theta \in[1,2)$ & -0.027 & -0.012 & -0.006 & -0.003 & -0.001 & $100.0 \%$ \\
$v_{0}=0, \theta \in[2,3)$ & -0.034 & -0.016 & -0.008 & -0.004 & -0.002 & $100.0 \%$ \\
$v_{0}=0, \theta \in[3,4]$ & -0.030 & -0.019 & -0.011 & -0.006 & -0.003 & $100.0 \%$ \\
\hline
\end{tabular}


(1) Firm 1's policy function, $\theta=2.2, k=2$

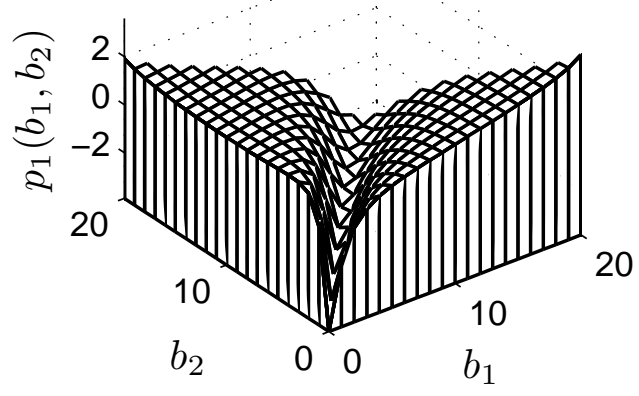

(3) Resultant forces, $\theta=2.2, k=2$

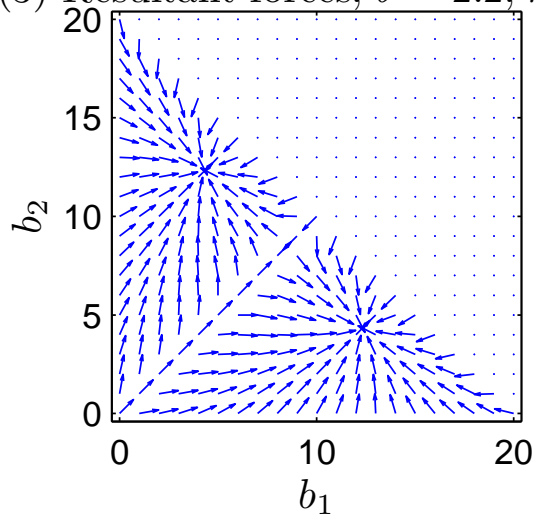

(5) Price time paths, $\theta=2.2, k=2$

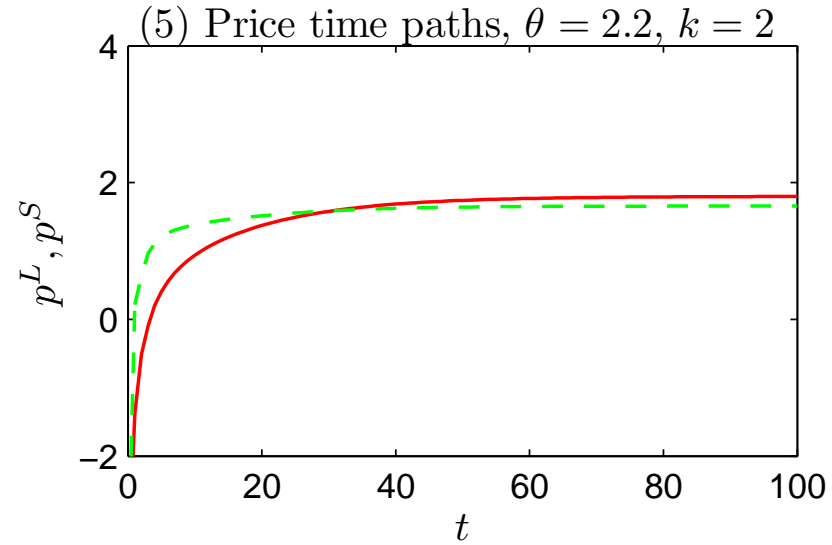

(7) Expected HHI

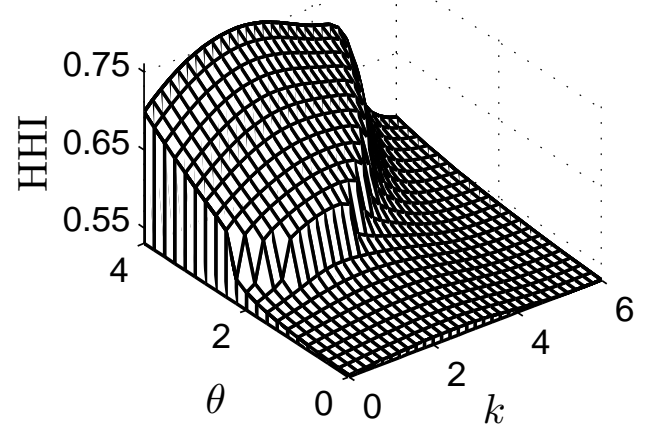

(2) Firm 1's policy function, $\theta=2.2, k=5$

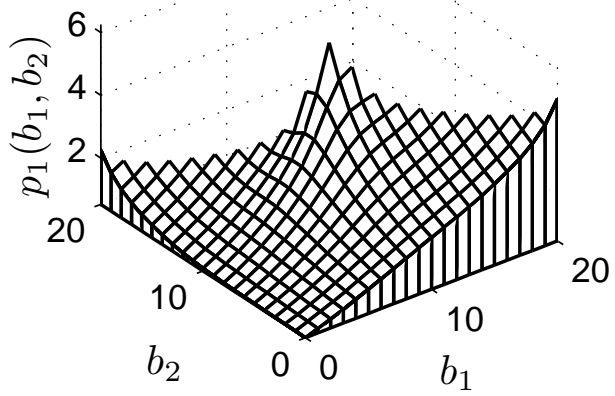

(4) Resultant forces, $\theta=2.2, k=5$

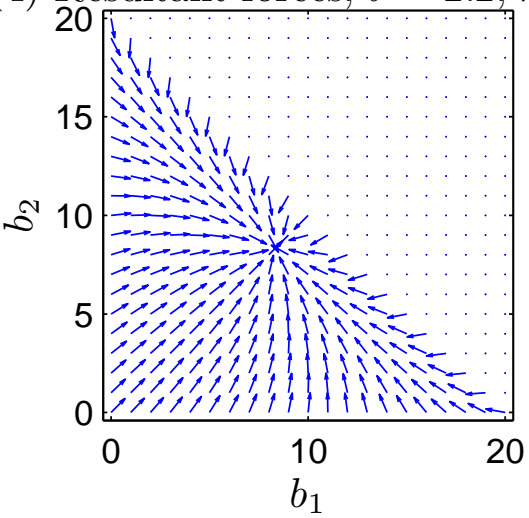

(6) Price time paths, $\theta=2.2, k=5$

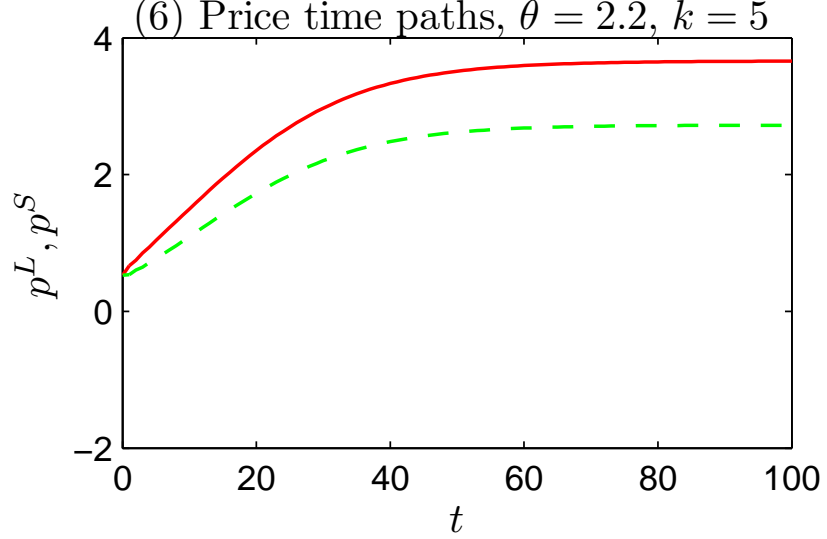

(8) Expected HHI, $\theta=2.2$

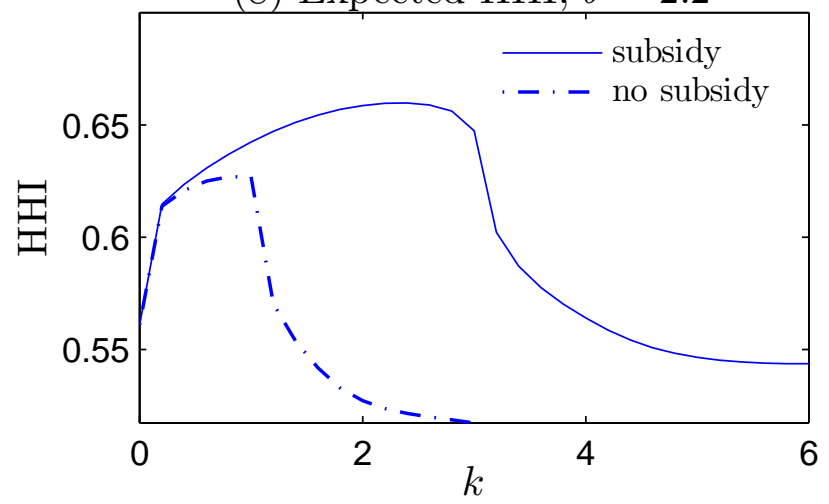

Figure A1. Switching cost subsidy. $v_{0}=-\infty, \delta=0.06, d=0.5$.

Top 3 rows: left column - Tipping equilibrim; right column - Peaked equilibrium. 